\title{
บ Usisersily
}

\section{Polyhydroxyalkanoates: Properties and chemical modification approaches for their functionalization}

Raza, Z. A., Riaz, S., \& Banat, I. M. (2017). Polyhydroxyalkanoates: Properties and chemical modification approaches for their functionalization. Biotechnology Progress, online. https://doi.org/10.1002/btpr.2565

Link to publication record in Ulster University Research Portal

\author{
Published in: \\ Biotechnology Progress
}

Publication Status:

Published online: 27/09/2017

DOI:

10.1002/btpr.2565

\section{Document Version}

Author Accepted version

\section{General rights}

Copyright for the publications made accessible via Ulster University's Research Portal is retained by the author(s) and / or other copyright owners and it is a condition of accessing these publications that users recognise and abide by the legal requirements associated with these rights.

\section{Take down policy}

The Research Portal is Ulster University's institutional repository that provides access to Ulster's research outputs. Every effort has been made to ensure that content in the Research Portal does not infringe any person's rights, or applicable UK laws. If you discover content in the Research Portal that you believe breaches copyright or violates any law, please contact pure-support@ulster.ac.uk. 


\section{Chemical modification of polyhydroxyalkanoates for multi- purpose applications}

\begin{tabular}{|r|l|}
\hline Journal: & Biotechnology Progress \\
\hline Manuscript ID & Draft \\
\hline Wiley - Manuscript type: & Review \\
\hline Date Submitted by the Author: & n/a \\
\hline Complete List of Authors: & $\begin{array}{l}\text { Raza, Zulfiqar; National Textile University, Applied Sciences } \\
\text { Riaz, Shahina } \\
\text { Banat, IM,; University of Ulster, School of Biomedical Sciences }\end{array}$ \\
\hline Keywords: & Chemical, PHAs, PHB, Polyhydroxyalkanoates, Polyhydroxybutyrates \\
\hline
\end{tabular}




\title{
Chemical modification of polyhydroxyalkanoates for multi-purpose applications
}

\author{
Zulfiqar Ali Raza ${ }^{1}{ }^{*}$, Shahina Riaz ${ }^{1}$ and Ibrahim M. Banat ${ }^{2}$ \\ ${ }^{1}$ Department of Applied Sciences, National Textile University, Faisalabad-37610, Pakistan \\ ${ }^{2}$ School of Biomedical Sciences, University of Ulster, Coleraine BT52 1SA, Northern Ireland, \\ UK
}

Running head: Chemical modification of polyhydroxyalkanoates

\begin{abstract}
Polyhydroxyalkanoates (PHAs) have become an attractive biomaterial in research in the past few years due to their extensive potential industrial applications. Being long chain hydroxyl fatty acid molecules, the PHAs are hydrophobic in nature, and have less functional groups. These features limit their applications in various areas. To enhance their usage, these polymers may need to be modified including surface and chemical modifications. Such modifications may alter their mechanical properties, surface structure, amphiphilic character and rate of degradation to fulfil the requirements for their future applications. Chemical modifications allow incorporation of functional groups to PHAs that could not be introduced through biotechnological methods. These chemically reformed PHAs, with enhanced properties could be used for broad range of applications. This review presents different chemical modification approaches for PHAs as possible technologies for widening the range of product and application potentials.

Keywords: Chemical; PHAs; PHB; Polyhydroxyalkanoates; Polyhydroxybutyrates

* Corresponding author: Tel: +92 41 9230081, Fax: +92 41 9230098, E-mail address: zarazapk@yahoo.com
\end{abstract}

\section{Contents}

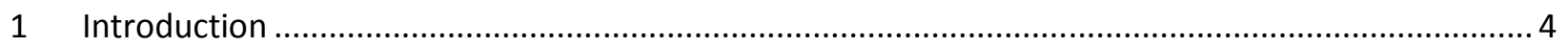

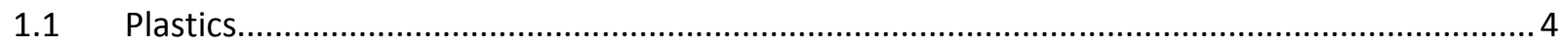

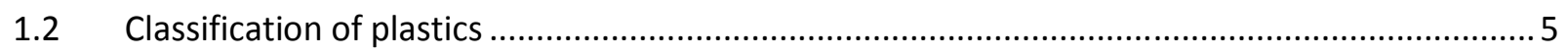

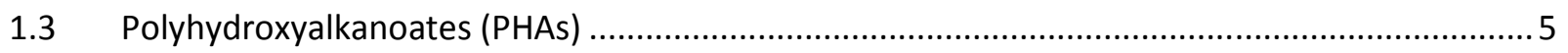

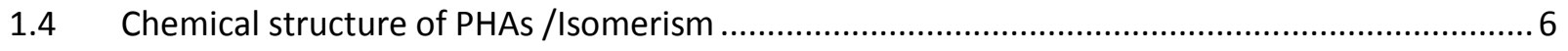

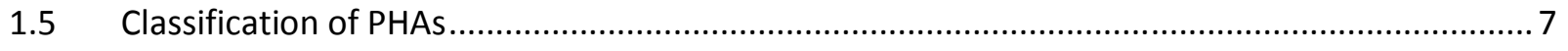

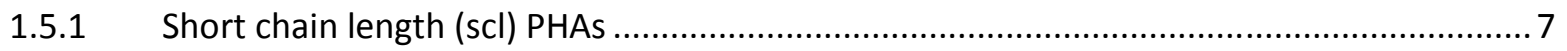




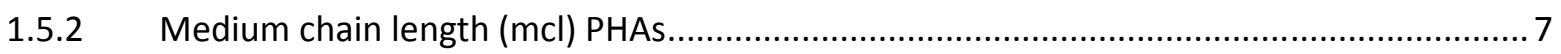

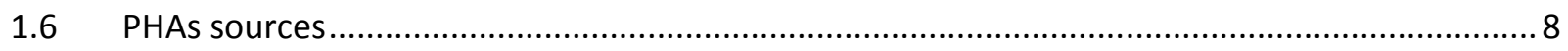

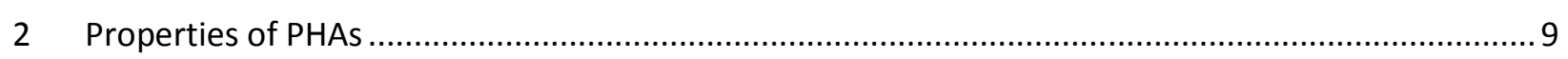

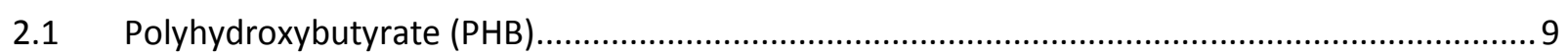

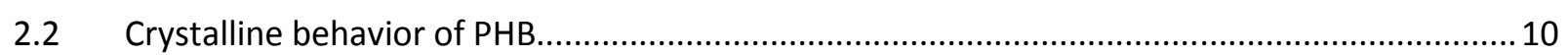

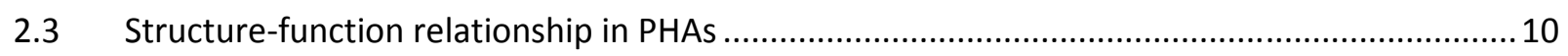

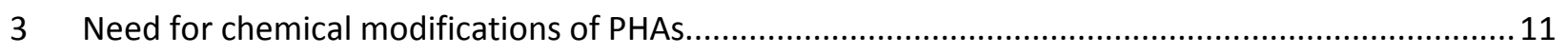

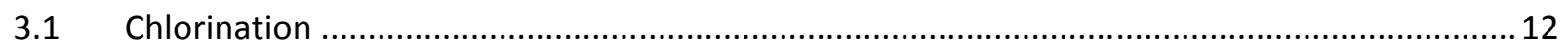

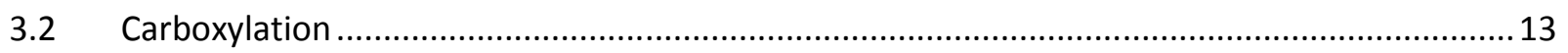

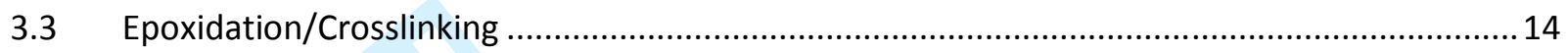

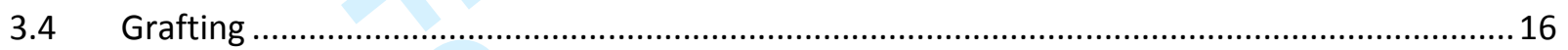

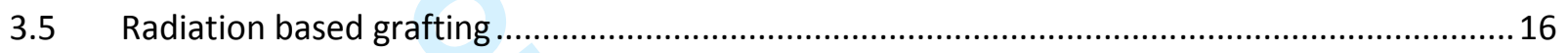

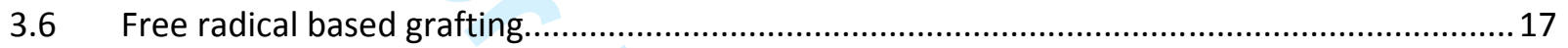

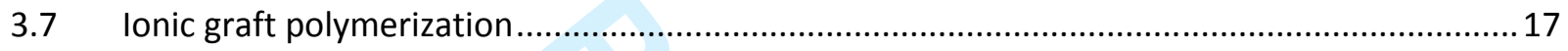

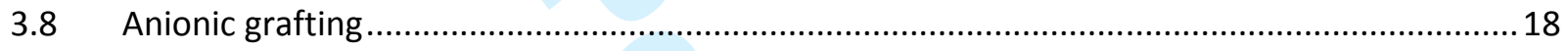

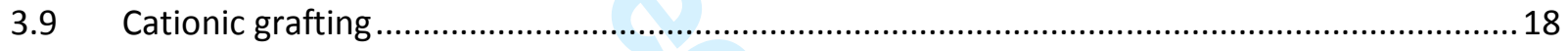

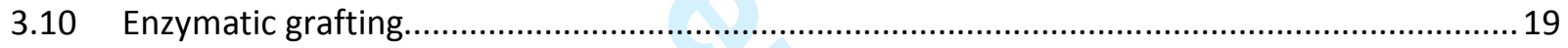

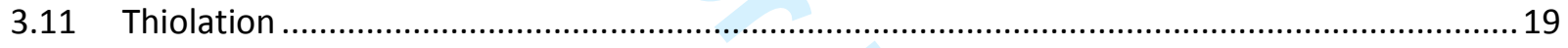

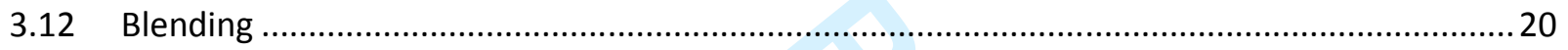

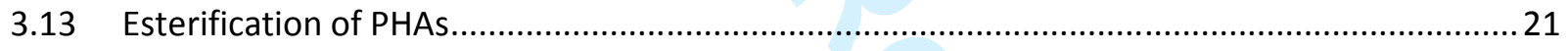

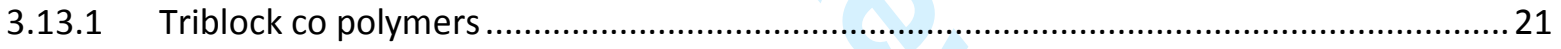

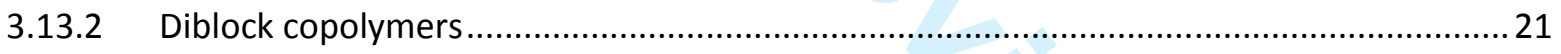

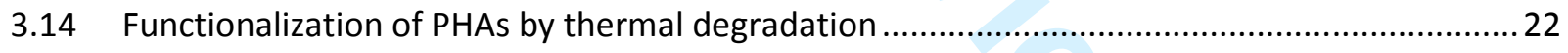

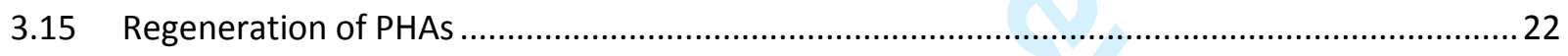

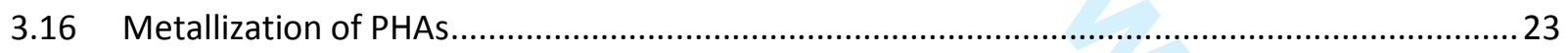

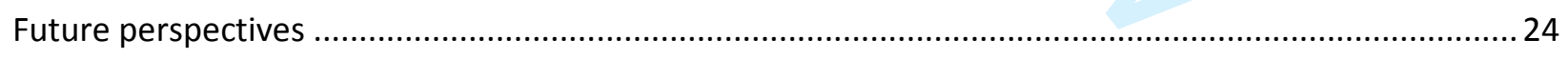

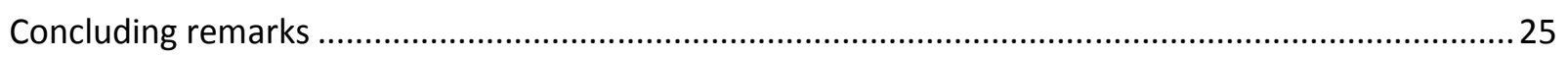

\section{List of abbreviations}

AAs $=$ Alkanoic acids

ABCs = Amphiphilic block copolymers

$\mathrm{AcHC}=$ Acetylehomocysteine

$\mathrm{ATBC}=$ Amphiphatic triblock copolymer

bio-PE = Bio-polyethylene

bio-PET = Bio-polyethylene terephthalate

$\mathrm{BCA}=$ Butyl cyanoacrylate 
$\mathrm{BL}=$ Butyrolactone

BuMA = Butyl methacrylate

$\mathrm{CdS}=$ Cadmium sulfide

$\mathrm{CS}=$ Chitosan

DMF $=$ Dimethyl formamide

DEG = Diethylene glycol

EDMA = Ethylene dimethacrylate

EDS = Electron donating substituents

$\mathrm{EG}=$ Ethylene glycol

$\mathrm{EO}=$ Ethylene oxide

PHA-LE $=$ Epoxidized linseed oil based PHA

2E4MI = 2-ethyle-4-methyleimidazole

$\mathrm{ENR}=$ Ethylene propylene rubber

3-HA = 3-hydroxyalkanoate

3-HB = Hydroxyl acids

HDP $=$ Hydroxylated PHB

3 -HV $=3$-hydroxyvalerate

2-HP = 2-hydroxypropanoate

3-HP = 3-hydroxypropanoate

LDP $=$ Low density polysaccharides derivatives

PHA-L = Linseed oil based PHA

MA = Malic acid

MeA = Methacrylate

MNPs = Metal nanoparticles

$\mathrm{m}-\mathrm{CPBA}=$ Meta chloroperoxybenzoic acid

$\mathrm{C} 1=$ Methyl

$\mathrm{mcl}=$ Medium chain length

$\mathrm{mPEO}=$ Monomethoxy polyethylene oxide

NPs = Nanoparticles

NNDCHC = 1,3-N,N- dicyclohexylcarbodiimid

$\mathrm{PBS} / \mathrm{A}=$ Polybutylene succinate/Adipate

PBCA = Poly $($ butyle cyanaoacrylate

$\mathrm{PECH}=$ Polyepichlorohydrin

PHAS = PHA synthase

PHAs = Polyhydroxyalkanoates

PCL = Polyhydroxybutyrate

PHBV = Polyhydroxybutyrate-co- valerate

$\mathrm{P}(3 \mathrm{HB}-\mathrm{co}-3 \mathrm{HV})=\mathrm{Poly}(3-$ hydroxybutyrate-co-3-hydroxyvalerate $)$

$\mathrm{PE}=$ Polyethylene

$\mathrm{P}(3 \mathrm{HHx}-\mathrm{co}-3 \mathrm{HO})=\mathrm{Poly}(3$-hydroxyhexanoate-co-3-hydroxyoctanoate $)$ 


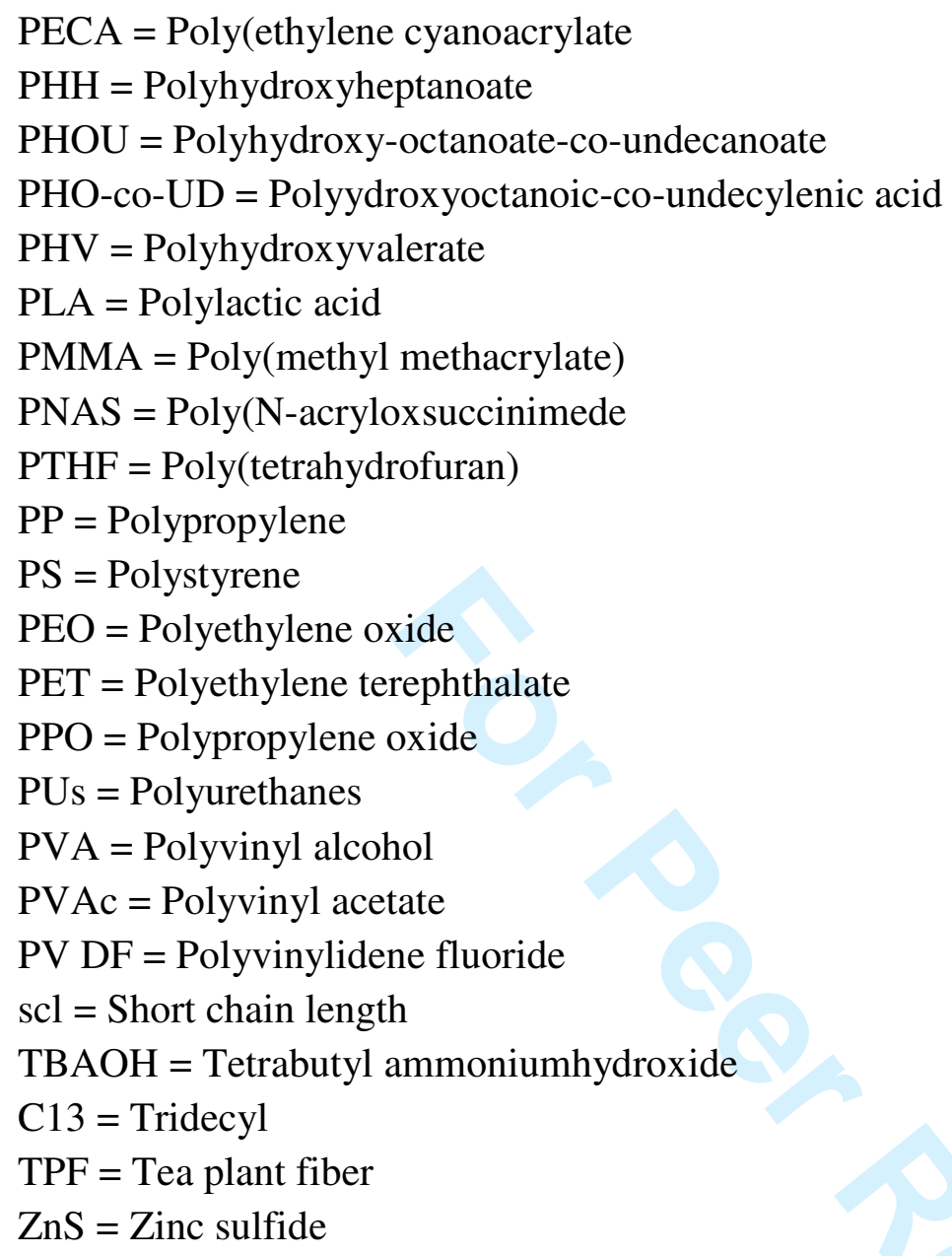

\section{Introduction}

\subsection{Plastics}

Plastics are used in almost all industries across the spectra ranging from home, gardens, building, medical and transport. To obtain a wide range of strength and shapes, the structure of plastics can chemically be manipulated to achieve the required characteristics. Most of the polymers, such as polyethylene compounds (PE), polypropylene compounds (PP), nylon and polyvinyl chloride (PVC) are used as plastics in many industries. The molecular weight range of plastics range from 50,000 to 1,000,000 Dalton. The main disadvantage of plastics is their cost effectiveness as material easy to produce and dispose-off upon use. Plastics are basically xenobiotic and mostly resistant to biodegradation and can persist in soil for long period of time. In last few years, public apprehension has increased over the destructive effects of petroleum based plastic products on the environment (Reddy et al., 2003). 
Concerns over plastics synthetic petroleum based plastics therefore have giving impetus to ecofriendly bio-based and biodegradable plastics produced from renewable resources that can biodegrade in the environment. Biodegradable plastics are of different types, photodegradable, starch-linked, semi-biodegradable and completely biodegradable. Ultraviolet (UV) radiations are necessary for the degradation of photodegradable plastics because they have a light sensitive group which is directly assimilated into the structure of polymer. As plastics are thrown into landfills, due to nonexistence of sunlight in landfills, these plastics keep on non-degraded (Pillai et al., 2011). Starch-linked polymers are semi-biodegradable; it is assumed that starch linked plastics are disposed of into landfills where starch is attacked by soil bacteria and released polymer segments that could be degraded by some bacteria. The eco-friendly plastics are novel and includes polyhydroxyalkanoates (PHAs), poly(lactic) acids (PLAs) and polysaccharides etc. (Reddy et al., 2003).

\subsection{Classification of plastics}

Basically, there are four main classes of plastics depending upon degradability and source. Figure 1 shows the classification of plastics. These are bio-based bio-degradable, bio-based nonbiodegradable, oil-based bio-degradable and oil-based non-biodegradable polymers. Typical oil based non-biodegradable plastics include polyethylene (PE), polypropylene (PP), polystyrene (PS) and polyethylene terephthalate (PET). However, poly(caprolacton) (PCL), poly(butylene succinate/adipate) PBS/A and PBS-co-terephthalate come under the category of oil-based biodegradable polymers. The bio-based non-biodegradable plastics are high density polysaccharides derivative (HDP), bio-poly(ethylene) bio-PE, bio(polyethylene terephthalate) bio-PET and polyurethanes. Forth class of plastics include poly(lactic acid) PLA, low density polysaccharides derivatives (LDP) and polyhydroxyalkanoates (PHAs)

Among all the four classes bio-based biodegradable plastics are preferred as they are considered as eco-friendly plastics. PHAs are considered as more eco-friendly plastics than other bio-based plastics; they are produced by microorganism and could easily be degraded by them.

\subsection{Polyhydroxyalkanoates (PHAs)}

The PHAs are one of the biodegradable and biocompatible thermoplastics (Gamal et al., 2013). These are larger molecules which are produced by Gram-negative and Gram-positive bacteria (Madison and Huisman, 1999). Basically, the PHAs have ester linkages in their structure which 
are produced by many of different types of bacteria as an intra-cellular storing material for substantial amounts of carbon and energy (Tsuge, 2002).

PHAs possess unique properties one of these properties is their high biodegradability in various environments and are therefore of much interest as biodegradable polymer compounds. Without a doubt amongst biopolymers, the bio based polyesters represent an alternative for petrochemical thermoplastics. Most easily accessible PHAs have mostly been reported produced using microbial cultures grown on renewable materials in sterilized environments, however most current studies emphasis to use of waste materials for growth media (Bugnicourt et al., 2014).

\subsection{Chemical structure of PHAs /Isomerism}

The PHAs that have been investigated to date are mainly linear polyesters containing 3-hydroxy fatty acid monomers. An ester bond is formed by the reaction between carboxyl group of one monomer and hydroxyl group of another monomer unit (Figure 2) (Madison and Huisman, 1999). Hence, most of the PHAs produced by various microorganisms are of rectus (R) configuration (Kemnitzer et al., 1992). The most common representative of PHAs, polyhydroxybutyrate (PHB), is present mostly as in R configuration. However, sinister (S) PHB could also be synthesized by synthesizing copolymer with some stereo polymers. Kemnitzer $e t$ al., (1992) synthesize a random stereocopolymer of PHB with butyraolacton (BL). All of R and S BL were successfully synthesized in high enantiomeric purity, after polymerization, small racemization (about 5\%) was also observed. A study (Kemnitzer et al., 1992), resulted in the stereocopolymer with enhanced properties such as crystallinity and thermal stability. In PHAs the hydroxyl substituted carbon atom is of R configuration except in a few cases where chirality is absent. Figure 2 represents general structure of PHAs, in this figure R represents alkyl group that may vary from methyl (C 1) to tridecyl (C 13) group and may also be positioned at $\beta$ carbon (Madison and Huisman, 1999). There is great variation in the alkyl side chain which may be: aromatic, halogenated, epoxidized or other branched monomers (Choi and Yoon, 1994; Curley et al., 1996; Kim et al., 1992). These variations in the size and composition of side chain substituents are responsible for chemical modification of PHAs and for their wide diversification in applications. 


\subsection{Classification of PHAs}

PHAs are grouped into three discrete classes according to the chain length. The first of these is short chain length ( $\mathrm{scl}$ ) polymers with maximum five carbon atoms chain, obtained from several bacteria, such as Cupriavidus necator and Alcaligenes latus. The second class includes medium chain length (mcl) polymers, containing 6 to 14 carbon atoms in the chain, obtained from several bacteria such as Pseudomonas putida and Pseudomonas mendocina (Akaraonye et al., 2010). The third class include long chain PHAs having carbon atoms $>14$ mostly produced by the bacteria such as Shewanella oneidensis and Aureispira marina (Suriyamongkol et al., 2007) blends of PHAs in scl such as $\mathrm{P}(3 \mathrm{HB}-\mathrm{co}-3 \mathrm{HV})$ and in mcl-PHAs such as $\mathrm{P}(3 \mathrm{HHx}-\mathrm{co}-3 \mathrm{HO})$ are also found (Akaraonye et al., 2010).

\subsubsection{Short chain length (scl) PHAs}

PHB, is known as crystalline and brittle polymer, but the blends of PHAs have low crystallinity and increased flexibility and are categorized as scl-PHAs and mcl-PHAs. These blends are manufactured in different plants such as Arabidopsis and in cotton, corn cell culture, Brassica napus and in tobacco by accumulating PHAS from Ralstonia eutropha or Aeromonas caviae. These scl-PHAs were found to emit the light at $590 \mathrm{~nm}$ wavelength while mcl-PHAs emit light of $575 \mathrm{~nm}$ (Arai et al., 2002; H. Wu et al., 2003; Sciences, 1998).

Arai, Nakashita et al. (2002) carried out gene modification to get a copolymer (PHB-co-HV-co$\mathrm{HH}$ ) by the addition of a signal encoder (which can target peroxisome) to the last 10 amino acid at -COO terminal of spinach glycolate oxidase, this modified gene was then transferred to Arabidopsis thaliana through agrobacterium regulated conversion. This resulted in the expression of transgenic gene along with its protein in Arabidopsis plant and in the accumulation of scl PHA in its tissues as detected by GC-MS analysis (Arai et al., 2002).

\subsubsection{Medium chain length (mcl) PHAs}

The mcl-PHAs are polyesters of hydroxyl acids (HAs) formed primarily by Pseudomonads during uneven growth conditions. These mcl-PHAs have high degree of biocompatibility and biodegradability and are obtained from renewable resources. As compared to scl PHAs, mcl PHAs has improved mechanical properties such as decreased brittleness, decreased crystallinity, low glass transition temperature, high melting temperatures and poor tensile strength 
characteristics. Hence, these are more flexible materials. In short, these are elastomers, and due to these properties, these polymers may be suitable to biomedical applications e.g. cardiovascular applications along with controlled drug release. Functional moieties of mcl PHAs make them more versatile than other PHAs and could be modified more freely for particular applications (Byrom, 1987; H. Wu, Sheu, \& Lee, 2003; Koning, 1995; Rai et al., 2011 ).

The mcl-PHAs could be synthesized by three steps; in the first through increase in chain length by condensation of acyl-CoA with acetyl-CoA; in the second through degradation of fatty acid fatty acid through $\beta$-oxidation, this is the key alleyway at what time fatty acids are being used as substrates; and in the third through biosynthesis of fatty acids, which is the key step in biosynthesis of cheap carbon compounds (Klinke et al., 1999).

Alkanoic acids (AAs) are the base materials for mcl PHA's synthesis their beta oxidation intermediates result in the production of mcl PHAs. To achieve the production of mcl-PHAs in plants, a strain, Arabidopsis thaliana was transmuted by its specific synthesizing enzyme from Pseudomonas aeruginosa with the accumulation of a specific enzyme (carboxyl 34 amino acid) from the B. napus with an enzyme isocitrate lyase (ICL) (Mittendorf et al., 1998). Studies (Huijberts et al., 1992; Javers and Karunanithy, 2012; Mittendorf et al., 1998) proved that amended PHA synthase (PHAS) can be suitably directed to leaf form peroxisomes of the plants that are grown in light and to glyoxysomes of the plants that are grown in dark. Plants venting the PHAS have amassed electron additions in their glyoxysomes, leaf, peroxisomes and in vacuole also. The additions were analogous to additions of bacterial PHA. Spectrometric and gas chromatographic analysis proved that mcl PHAs are also present in transgenic plants. These demonstrations show that beta oxidation intermediates of AAs produce a wide assortment of hydroxy acyl acetyl-Co with R configuration which is the precursors for synthesis of mcl-PHA.

\subsection{PHAs sources}

PHAs are macromolecules which are produced by various species of microorganisms. More than 300 bacteria from family, Halobactericeae are some of the sources for PHAs synthesis (Suriyamongkol et al., 2007). Synthesis of PHAs involves three genes and three enzymes and is the simplest biosynthetic pathway (Peoples and Sinskey, 1989). Pseudomonas Oleovorans and Pseudomonas fragii are the bacteria which can synthesize mcl PHAs through the beta oxidation of alkanoic acids by providing hydroxyalkanoyl-CoA substrate (Lageveen et al., 1988; Peoples 
and Sinskey, 1989). Plant's peroxisomes give Ac-CoA via beta oxidation of fatty acid and provide a compartment for the synthesis of PHAs (Hahn et al., 1999)

Polyesters comprising 2-hydroxypropionate (2-HP), 3-hydroxypropionate (3-HP), 4hydroxybutyrate (4-HB), 3-hydroxyvalerate (3-HV), and mcl 3-hydroxyalkanoate (3-HA) monomers can all be manufactured in Escherichia coli by assimilating exogenous or endogenous alleyways and/or genes (Wang et al., 2013).

Bacterial production of PHAs is non-economical as compared to petroleum based plastics. Due to these reasons, there is interest in exploring production of PHAs in eukaryotic cells, specifically in crops. PHAs synthesis in insect and yeast cells explores the ideas that how these synthetic pathways can be introduced to plants. In a study, it was revealed that PHB is synthesized through the expression of PHB synthase gene in saccharomyces cerevisiae (Leaf et al., 1996). But the accumulation of PHB was less than $5 \%$ may be due inadequate specific enzymes (Poirier et al., 2001).

\section{Properties of PHAs}

The PHAs are attaining increased attention in the ecofriendly polymer market because of their favorable properties such as high biodegradability in various environs, not only in composting plants and processing versatility, Hence among biopolymers, these polyesters symbolize an future sustainable alternative for fossil fuel-based thermoplastics (Bugnicourt et al., 2014).

\subsection{Polyhydroxybutyrate (PHB)}

A French microbiologist Maurice Lemoigne was first to isolate and characterize PHB in 1925 (Lemoigne, 1926). PHB has optical activity and is stereoregular homopolymer. Among PHAs, PHB is the most well-known biodegradable and biocompatible polymer as it gains significant interest by industries. It is used in agriculture, house hold and medical industries for broad range of applications (Ashby et al., 2000). PHB is produced by remote type bacteria as linear, crystalline and amorphous forms. Its glass transition temperature is about $4{ }^{\circ} \mathrm{C}$ and its melting temperature is near $180^{\circ} \mathrm{C}$ having density and specific gravity of 1.26 and $1.18 \mathrm{~g} / \mathrm{cm} 3$ respectively. The mechanical possessions of this biopolymer are similar to isotactic polypropylene (Pfeiffer and Jendrossek, 2014; Sato et al., 2015). 
The molecular weight of PHB depends upon its source, growth situations and extraction method. Its molecular weight differ from 50, 000 to million (Rai et al., 2011). Organically created, PHB is a semi crystalline isotactic stereo systematic polymer with $100 \% \mathrm{R}$ configuration which permits enhanced degradability (Steinbüchel, 2005). Figure 3 shows general structure of PHB.

\subsection{Crystalline behavior of PHB}

PHB and other PHAs show crystallization when extracted from cell with some non-polar solvents while they remain as granules in cytoplasm. This crystallization behavior of PHB could be kinetically controlled and could be stopped by particles of submicron size or by coating of phospholipids and their proteins (Anderson \& Dawes, 1990; Doi, 1995)

\subsection{Structure-function relationship in PHAs}

PHAs are composed of long chain fatty acid monomers mostly 3,000 to 40,000 monomer units in straight chain fashion. Fatty acids having hydroxyl group at carbon-3 undergo beta oxidation and give Ac-CoA residues which undergo condensation by the action of certain enzymes forming PHAs. Depending upon the type of monomers synthetic pathways vary from monomer to monomer indicating that synthetic enzymes are broadly dispersed and that the creation of a specific polyester is an enzyme specific incident (Luengo et al., 2003).

When there is an inequity in the nutrients supply of a cell (increase in carbon concentration and limitation in $\mathrm{N}_{2}, \mathrm{P}$, and $\mathrm{O}_{2}$ ), bacteria stock these surplus nutrients intracellularly and yield water insoluble biopolymers. When normal environment is restored, these biopolymers become militarized (Diez-Pascual and Diez-Vicente; Hahn et al., 1997; Suriyamongkol et al., 2007; Sato et al., 2015).

The scl-PHAs have possessions in common with conservative plastics while, mcl PHAs are known as elastomers and rubber materials. The PHAs have some functionality through which monomers can be modified to give more versatile polymers such as introduction of unsaturation or halogenation of monomers. The properties of these polymers can be further improved. In addition homopolymers, hetropolymers can also be fabricated by the condensation of two or more than two different types of polymers. The most well-known representative of scl-PHAs is PHB. Blends of PHAs can also be manufactured such as polyhydroxybutyrate/polyhydroxyvalerate (PHB/PHV), 
polyhydroxybutyrate/polyhydroxyheptanoate (PHB/PHH) (Steinbüchel, 2005; Suriyamongkol et al., 2007; Kulkarni et al., 2011).

Properties of bacterial PHAs are comparable to those of polypropylene (PP) conventional plastics (Byrom, 1987). The catabolism of PHAs to $\mathrm{CO}_{2}$ and $\mathrm{H}_{2} \mathrm{O}$ is facilitated by the enzyme PHA depolymerases (Jendrossek and Handrick, 2002). PHAs are also considered as natural green plastics as they can be recycled and produced from renewable resources which makes them substituents to petroleum based plastics (Poirier, 1999). The great variety of monomers presented by PHAs gives an extensive spectrum of polymers with different physical possessions. Their physcio-chemical properties are governed by their monomeric structure that is determined by manufacturing microorganisms and their nutrition (Zinn and Hany, 2005).

PHB is a homopolymer with high level of crystallinity and brittleness. These properties make it of less use. PHAs of long chain fatty acid monomers, are elastic and sticky in nature, rubber can be generated by modification of these long chain PHAs. Elasticity of PHAs can also be increased by making the blends pf PHB with long chain PHAs such as hydroxyvalerate (HV) and hydroxyhexanoate (HHx) etc. These blends present more flexibility and toughness and can be used for the manufacturing of various products such as bottles and food packaging materials (Griffin, 1994).

As PHAs are biodegradable and have biocompatibility, they are degraded into 3-HA (3hydroxyacids) which are found in animal tissues. They have a number of applications in medical field such as in control drug release, implants and oesteosynthetic ingredients (Pouton and Akhtar, 1996; Sudesh, 2004) and can also be used as potential material in tissue engineering scaffolding (Williams et al., 1999) .

\section{Need for chemical modifications of PHAs}

PHAs are comparatively new group of biodegradable polymers with high impact in future because of their different properties. They are considered as more attractive biomaterials in research since last few years due to their extensive applications. As PHAs, are long chain hydroxy fatty acid molecules, therefore, they are hydrophobic in nature, have low degradability under certain biological environments and have less functional groups. These features limit the space of their applications in various areas (Hu et al., 1999; Jamieson et al., 2007; Królikowska 
et al., 2003; Mandal et al., 2006; Mohanpuria et al., 2008; Smith et al., 2008; Sweeney et al., 2004). To enhance their usage, these polymers are needed to be modified including surface and chemical modifications. These modifications may alter their mechanical properties, surface structure, amphiphilic character and rate of degradation to fulfil the requirements for their specific applications. Chemical modifications allow incorporating functional groups to PHAs that are not easily achievable through biological routes. These chemically reformed PHAs, with enhanced properties, can be used as multifunctional supplies. Different methods of chemical modifications includes epoxidation, carboxylation, chlorination, grafting (cationic, enzymatic, radiation based and free radical grafting), blending, esterification based copolymerization, incorporation of functional groups to PHAs through thermal degradation, metallization and thiolation (Bassas-Galià et al., 2015; Hazer and Steinbüchel, 2007; Kai and Loh, 2013). To date several studies have been carried out on PHA modification including physical and biological modifications. Hence the functionalities of available PHAs have been broadly extended by chemical modification methods. Some chemical modification methods are discussed below and are presented in Table 1 which summarizes these chemical modification methods and properties achieved by each.

\subsection{Chlorination}

Chlorination is the process of introducing or adding chlorine to a substrate. In the case of polymers, unsaturated PHAs can undergo chlorination or saturated PHAs can undergo chlorination by substitution reaction. Arkin et al., (2000) carried out chlorination of unsaturated PHA was carried out by producing chlorine gas and passing through the PHA solution in chloroform at room temperature and sunlight. This study revealed that as the extent of chlorination increased, properties of PHA changed from soft and sticky to crystalline, brittle and hard. The chlorinated PHA would serve as a very useful intermediate for blending of polymers and for further modifications such as carboxylation ( Doi and Abe, 1990).

In a different study, PHB and PHO chlorination was carried out by substitution reaction. In this study chlorine gas was passed through the polymers solution in chloroform. This resulted in molecular weight loss of polymers due to hydrolysis. Glass transition temperature and melting temperatures of chlorinated PHO was significantly increased while melting temperature of PHB was decreased from $170^{\circ} \mathrm{C}$ to $148^{\circ} \mathrm{C}$ and its glass transition temperature changed from $-20{ }^{\circ} \mathrm{C}$ to 
$10{ }^{\circ} \mathrm{C}$. when these chlorinated polymers were further subjected to modification such as PHAquaternary ammonium salts, NaSO4 salts, phenyl derivatives were obtained. These chlorinated PHAs could also undergo Friedel-Crafts reactions with benzene to produce cross-linked polymers (Arkin and Hazer, 2002;Hazer and Steinbüchel, 2007). Hence chlorination is the simplest method of modification for PHAs.

\subsection{Carboxylation}

Carboxylation is the process of introducing carboxylate functional group in a substrate. PHAs with unsaturated side chains, chlorine groups or epoxidized side chains can be subjected to oxidation resulted in carboxylation of PHA with increased hydrophilicity. To bind target enzymes, hydrophilic constituents or biologically active molecule and carboxylic groups serve as the most active functional groups. Insertion of these functional groups to polymers resulted in increased hydrophilic character of the polymer. Almost 70 PHAs had been discovered that have such -COO group and OH end group (Kai and Loh, 2013; Zook and Kee, 2016).

Bacterial PHAs are hydrophobic in nature; their hydrophobicity can be reduced by some chemical methods. Stigers and Tew, (2003), reported carboxylation of an unsaturated copolymer PHO-co-PHU using $\mathrm{OsO}_{4}$ and oxone. This oxidation was carried out in warm dimethylformamide (DMF) and resulted in some backbone degradation; this degradation was confirmed by NMR and GPC. This carboxylation was also confirmed by solubility of polymer before and after carboxylation in different solvents such as THF, $\mathrm{H}_{2} \mathrm{O}$ and acetone.

Carboxylation of unsaturated PHOU was also carried out by using potassium permanganate as an oxidizing agent at $558^{\circ} \mathrm{C}$ and resulted in loss of molecular weight of the polymer. IR and 1 HNMR spectroscopic technique was used to confirm carboxylation. The extent of carboxylation was varied with time, e.g. after $2 \mathrm{~h}$, almost $50 \%$ carboxylation occurred. The hydrophilicity of polymer was increased and it was confirmed by its solubility in water (Lee and Park, 2000). In short, carboxylation could be utilized whenever there is a need to change hydrophobicity/hydrophilicity levels. In this regard, this method could be used for the preparation of hydrogels. 


\subsection{Epoxidation/Crosslinking}

Epoxides are also known as oxiranes. The epoxy groups are very reactive functional moieties, and are important organic intermediate in industries. They could be used in many polymer reactions without degradation of polymer. Linseed oil based (PHA-L) mcl-PHA have low molecular weight and high degree of unsaturation in side chain. These are amorphous in nature and have considerable viscosity at room temperature. The unsaturated side chains of these PHAs were subjected to epoxidation by using meta-chloroperoxybenzoic acid (m-CPBA) as a crosslinker, to enhance the properties and applications of these PHAs. Approximately $37 \%$ olefinic the groups were converted to epoxy groups. These epoxy groups increase the chances of crosslinking for PHAs, when they are exposed to air. Analytical results revealed that the linseed oil based epoxidized PHA (PHA-LE) enhanced tensile strength and young's modulus than linseed based PHA (PHA-L) (Ashby et al., 2000). Hence, epoxide function is highly reactive and could be successfully used for further reactions such as crosslinking which is defined as chemical joining of two molecules by covalent bond (Park et al., 1998). . In the case of polymers, it could also be defined as formation of new chemical bond of one polymer with another polymer. The presence and extent of crosslinking in a material often have significant effects on its chemical and mechanical properties (Nicholson, 2012).

Arkin et al. (2000) subjected polyhydroxyoctanoate-co-10-undecanoates (PHOUs) to epoxidation due to the presence of vinyl group which easily undergo epoxidation reaction and copolymers were obtained by using (m-CPBA). The epoxidized copolymers contained up to 22 mol \% repeating units. These epoxidized polymers were subjected for crosslinking with anhydride of succinic acid and 2-ethyl-4-methyleimidazole (2E4MI) used for crosslinking reaction initiation. Reversibility and degradation of reaction was avoided by using mild reaction conditions (temperature $90^{\circ} \mathrm{C}$, for $1-4 \mathrm{~h}$ ). An increase in sol gel (involving alternation between sol and gel contents) contents and in glass transition temperature indicated Crosslinking. Ozawa and Kissinger methods were used for kinetic study of the epoxidation reaction and the values for the activation energy and frequency parameters were high obtained by Ozawa method than by Kissinger method.

A mcl-PHA obtained from palm oil was permitted to come in reaction with epoxidized natural rubber (ENR). The reaction did not occurr at normal temperature for a short period of time, 
however with time as temperature was increased to $170^{\circ} \mathrm{C}$, thermal degradation of mcl-PHA started and smaller units of polymer (carboxylic acid terminals) were obtained that resulted in the ENR ring opening (Lee et al., 2010).

To increase the elastic properties of the two different types of PHAs (saturated and unsaturated) polyhydroxy-octanoate (PHO) and PHO-co-UD (polyhydroxyoctanoic-co-undecylenic acid), were subjected to peroxide crosslinking in the presence and absence of a different functional cross-linkers. The extent of crosslinking was determined by using sol-gel analytical technique; this technique verified crosslinking and demonstrated that variation in crosslinking was due to peroxide type and its concentration. DSC revealed that all the crystallinity in polymers was removed by crosslinking; in short crosslinking resulted in decreased tensile strength and also decreased tear resistance (Gagnon et al., 1994).

In another study, composite of PHA with malic anhydride (PHA/MeA) crosslinked with tea plant fiber (PHA-g-MeA/t-TPF) was assessed; it was observed that PHA-g-MA/t-TPF has more enhanced mechanical properties than PHA/TPF due to high compatibility with TPF. It was also apparent that t-TPF had more dispersion homogeneity in the matrix of PHA-g-MeA due to ester linkage formation which resulted in creation of cross-linked and branched larger molecules among $-\mathrm{COOH}$ and $\mathrm{OH}$ groups of PHA/MeA and t-TPF respectively. This crosslinked composite had more polished properties such as increased water resistance, easy processing because of low viscosity and high biodegradability with an increase in TPF contents (Wu, 2013).

Similarly, a study was conducted to fabricate an unsaturated composite PHB/PHBU produced by Escherichia coli strain which was subjected to cross-linking through thiolene click chemistry and was analyzed for enhanced physical material goods and its biocompatibility with human mesenchymal stem cells. A significant increase in tensile strength was observed which was compatible to material with properties required for replacement of soft tissue. In that study (Levine et al., 2015), it was also revealed that this chemically modified material did not possess toxicity towards human cells after cross-linking. Hence, crosslinking and epoxidation are linked with each other and considered more suitable and basic methods for the modification of PHAs. 


\subsection{Grafting}

Grafting is a technique in which covalent bond exist between monomers and another polymer chain to obtain desired properties. Polymers properties are broadly different depending on their chain structure. Figure 4 shows general mechanism of grafting. A copolymer is comprised of two different polymer units; in case of graft copolymers one or more side chains are attached to the main chains as its blocks. Grafting is a convenient way to synthesize a copolymer with new properties with minimum loss of original properties of the polymer (Macit et al., 2009). Different types of grafting methods are discussed below.

\subsection{Radiation based grafting}

Radiation based grafting follow the irradiation of a pure monomer through ionizing radiations or by high energy source. Carboxyl groups of PHAs are reactive sites and readily reacts with the amine groups of polysaccharides such as cellulose and chitosan (Yalpani et al., 1991). As PHB is brittle, crystalline and moderately hydrophobic therefore, it often requires some chemical modifications for certain applications, one of these modifications is its graft copolymerization. In a study, grafting of two selected monomers methacrylate (MeA) and butyle methacrylate (BuM) on PHB was carried out by using radiation based graft copolymerization. This study revealed successful grafting on PHB. The grafted PHB was less crystalline because of the hindrance provided by BuM and MeA. Water uptake was also observed which indicates increased hydrophilicity (Gonzalez et al., 2009)

As PHB is chemically inactive polyester, chitosan (CS) could be grafted onto PHB using gamma irradiation along with different solvents (acetone, ethyl acetate and acetic acid) as a suitable method. NMR analysis showed possible P(3HB-g-CS) structure. Per this study (Torres et al., 2015 ethyl acetate was the most suitable solvent for grafting of CS on PHB while, acetone proved to be unsuitable solvent for this purpose. This study Torres et al., 2015) concluded a direct relationship between crystallinity and grafting. However, radiation-based grafting polymerization reactions are not convenient at large scale, therefore chemically induced reactions are preferred (Allcock et al., 2003) .

When PVA was grafted onto PHB using gamma rays irradiation with different solvents, the grafted PHB showed variation in different properties such as formation of cavities, surface roughness, and formation of waves. N-hexane was more suitable solvent for grafting. This study 
concluded that biodegradability of grafted PHB can be enhanced with increased grafted PVA concentration (Torres et al., 2015).

\subsection{Free radical based grafting}

In radical grafting, a growing polymer chain has an unpaired electron which becomes a radical site to react with the unsaturated part of coming monomer. In this way the unpaired electron gets transferred to the incoming monomer (Allcock et al., 2003)

In chemical reactions, free radicals are generated by the initiators and is transferred to the substrate to react with the monomer resulting in a grafted copolymer. General mechanism for free radical generation by redox process through $\mathrm{M}^{\mathrm{n}+} / \mathrm{H}_{2} \mathrm{O}_{2}$, persulphates is presented as follows:

$$
\begin{aligned}
& \mathrm{Fe}^{+2}+\mathrm{H}_{2} \mathrm{O}_{2} \rightarrow \mathrm{Fe}^{3+}+\mathrm{OH}^{-}+\mathrm{OH}^{\circ} \\
& \mathrm{Fe}^{+2}+-\mathrm{O}_{3} \mathrm{~S}-\mathrm{OO}-\mathrm{SO}_{3} \rightarrow \mathrm{Fe}^{3+} \mathrm{SO}_{4}{ }^{2-}+\mathrm{SO}_{4}^{-\circ}
\end{aligned}
$$

Regarding the activity of $\mathrm{SO}_{4}^{-\circ}$, authors have different views, one suggests that the produced $\mathrm{SO}_{4}{ }^{-\circ}$ react with water to give $\mathrm{OH}^{\circ}$ with subsequent production of free radicles on the backbone of polymer. An alternative view suggests that the $\mathrm{SO}_{4}{ }^{-\circ}$ directly reacts with polymer backbone to generate required the radicles as:

$$
\mathrm{SO}_{4}^{-\circ}+\mathrm{R}_{\text {polymer }}^{-} \mathrm{OH} \rightarrow \mathrm{HSO}_{4}+\mathrm{R}_{\text {polyme }} \mathrm{r}^{-} \mathrm{O}^{\circ}
$$

This radicle containing polymer reacts with incoming monomer to give grafted copolymer (Bhattacharya and Misra, 2004)

S. Nguyen and R.H. Marchessault (2006) successfully synthesized graft copolymer of PHB and poly(methyl methacrylate) (PMMA) using free radical based grafting mechanism. This synthesized copolymer had a comb shape and exhibited huge changes in its glass transition temperature (Tg) from $100^{\circ} \mathrm{C}$ to $3^{\circ} \mathrm{C}$ (Nguyen and Marchessault, 2004). Figure 5 shows general mechanism of radiation based grafting of PHB. Overall, free radical grafting is much better understood in fundamental and mechanistic sense, however this method of grafting is not specific.

\subsection{Ionic graft polymerization}

Ionic grafting is a specific ion based grafting which includes cationic and anionic polymerization reactions. In anionic polymerization, the growing polymer chain possesses a negative or positive 
charge. In case of cation based grafting, stable cation could be generated if the initiator has electron donating substituents (EDS). These EDS stabilize the delocalization of positive charge in $\pi$-orbitals of a double bond. While, in anion based grafting the initiator should have an electron withdrawing substituent (EDS) in order to generate a stable carbanion, if the resonating and inductive structures were obtained simultaneously, the stability will be significantly increased (Cowie and Arrighi, 2007). Figure 6 shows general mechanism of cationic and ionic polymerization.

\subsection{Anionic grafting}

Anion graft polymerizations are those in which the growing polymer chain contains a negative charge. Anionic catalyst or initiators are required to start anionic graft polymerization reactions of which the most commonly used initiators includes alkali metal suspensions, Grignard reagents, Zieglar-Natta catalyst, metallocene initiators and organic radical anions. The graft polymerization process follow the typical procedure started from initiation step through dimerization step ending with a propagation step.

Kowalczuk et al (1994) successfully grafted beta-butyrolacton onto poly(methyl-methacrylate) PMMA by through anionic grafting. He observed that PMMA was partially sponified and it contained a carboxylate group. This carboxylate anion made a complex with 18-crown-6potassium which acted as an initiator for the grafting of beta-butyrolacton onto PMMA. The grafted copolymer was successfully achieved at high yields (Kowalczuk et al., 1994).

Anionic grafting offers some stereo control grafted copolymers; narrow molecular weight distribution and block copolymers are also accessible via "living polymers" (polymers which can propagate and grow to a desired size and their degree of termination or chain transfer is still negligible). Disadvantage of anionic grafting include requirements for low temperature and is only feasible for limited number of polymers (Allcock et al., 2003)

\subsection{Cationic grafting}

Cation graft polymerization occurs in growing chain containing a positive charge. Cationic initiators or cationic catalyst plays major role in these polymerization reactions. Mostly, strong protonic acids, Lewis acids and their complexes are used for this purpose. The process includes initiation, propagation, chain transfer and an end termination step (Allcock et al., 2003). 
Combination of cationic and free radical based grafting was used to synthesize a multi-graft copolymer. In a study, polyhydroxyalkanoate-g-(poly(tetrahydrofuran)-b-poly(methyle methacrylate) (PHA-g-(PTHF-b-PMMA) multi-graft copolymer was achieved, carbonium cation was used for the initiation of cationic polymerization of THF onto PHA (PHA-g-PTHF). This graft copolymer was with hydroxyl end groups because the carbonium cation was generated from PHBV and PHBx. In the presence of cerium salts these hydroxyl end copolymers can start redox polymerization of polymethyle methacrylate (MMA) and PHA-g-(PTHF-b-PMMA) graftcopolymer would be achieved (Macit et al., 2009). Cationic grafting has the main advantage of controlling molecular weight of a grafted copolymer. But this grafting process is limited only to the olefins and is moisture sensitive along with requirement of low temperature requirement to start the reaction (Allcock et al., 2003).

\subsection{Enzymatic grafting}

Among physical and chemical grafting approaches, enzymatic grafting approach is more promising as it usually less hazardous when compared to the risky chemical approaches (Aljawish et al., 2012). Laccases are blue color copper oxidases, capable to interactions with a wide diversity of appropriate substrates. Their commercial accessibility, wide oxidative abilities and potent abilities for surface amendments make them smart contenders for an extensive series of applications (Arora and Sharma, 2010Riva, 2006). Laccase based grafting of ethyl cellulose onto the surface of PHB was investigated using enzymatic grafting demonstrated that enzymatic grafting is ecofriendly and energy saving process for grafting providing a suitable environment for polymer grafting providing products with multiple functionalities (Iqbal et al., 2014).

\subsection{Thiolation}

Thiolation is the process of introducing disulfide bond or sulfhydryl group to the substrates that may be a polymer such as PHAs. Jaffamines (polymer) are linear or unbranched chains of hydrocarbons with an ionizable amino group biocompatible and could be easily grafted on to other polymers. Thiolation was used for grafting of jaffamine onto PHOU which was first methylated and subjected for thiolation using acetylehomocysteine (AcHC) and thiolactone. This resulted in the conversion of amino group of jaffamine into thiol which was then grafted onto PHOU by photografting method. The resulted copolymer was amphiphilic in nature and thermosensitive (Azzam et al., 2010; Caldwell et al., 1997; Le Fer et al., 2012). 
Ethylene dimethacrylate (EDMA) was also grafted onto the surface of poly $(\mathrm{N}$ acryloxsuccinimede) (PNAS) through thiol-ene-click chemistry. Thiol bearing ethylene glycol (EG) was used as thiol source. The reaction was initiated through UV irradiation and toluene was used as porogenic solvent. After polymerization allyl amine was grafted and an allyl containing, thiolation sensitive monolith poly(NAS-co-EDMA) was obtained. This monolith could be used as stationary phase in hydrophilic interaction chromatography and the thiolated copolymer can be further conjugated with other polymers to get more functional copolymers (Le Fer et al., 2012; Tijunelyte et al., 2012).

\subsection{Blending}

Blending of polymers gives exciting potentials to obtain economical and biodegradable materials with attractive mechanical properties. Many of studied have been carried out PHAs co-polymers especially blends of PHB with other different polymers. A systematic study was conducted to fabricate blends of PHB for biomedical applications (Yu et al., 2006). The growth of fibroblast mice cells was observed on PHB and poly(hydroxybutyrate-co-polyhydroxyhexanoat) (PHBHHx) films and on their blends, were investigated. This study demonstrated that cellular growth was significantly increased on blends of PHB/PHBHHx than on independent PHB and PHBHHx which indicated better biocompatibility of blends (Yang et al., 2002). A dramatic increase in the tensile strength in the films of blends of PHB/PHBHHx was also observed with the increase of PHBHHx contents (Deng et al., 2002).

In a study blends of PHB/ethylene-propylene rubber (EPR) and PHB/PVAc it was reported that PHB/PVAc blends are compatible while that of PHB/EPR were immiscible, therefore PHB/PVAc blends showed single Tg value and exhibit a depression in their melting point. In case of PHB/EPR, PHB spherulites was observed with no change in their morphology (Kumagai and Doi, 1992; Paglia et al., 1993). Similar type of miscible and immiscible hybrids of PHB with some dissimilar polymers such as $\mathrm{PHB} /$ poly(epichlorohydrin) (PECH), $\mathrm{PHB} /$ polyvinylidene fluoride(PVDF), PHB/PEG, PHB/PMMA were also reported (Abbate et al., 1991; Chiu et al., 2001; Goh, 2014; Hay and Sharma, 2000; Kumagai and Doi, 1993; Paglia et al., 1993; Sadocco et al., 1993). 


\subsection{Esterification of PHAs}

\subsubsection{Triblock co polymers}

Amphipathic block copolymers (ABCs) signify a unique group of efficient polymers that are exclusive building blocks aiding a number of applications principally linked with energetic and structural controller of materials interfaces (Forster and Antonietti, 1998). Two chains of methoxy-PEO- hydroxylated PHB (PHB-OH) sequence by using 1,3-N,N'dicyclohexylcarbodiimid (NNDCHC) were linked together to make an amphipathic triblock copolymer (ATBC). PHB-OH was achieved by the reaction PHB with diethylene glycol (DEG) (transesterification reaction) using dibutyltin dilaurate as a catalyst (Andrade et al., 2002). Thermogravimetric analysis indicated that the degradation of ATBC occurred in two distinct phases for PHB and PEO blocks. This analysis also revealed that the ATBC have enhanced thermal stability compared with the originators (Li et al., 2003). A blend of epoxy resin (ER) (bisphenol type) and TBC PEO-PPO-PEO in ester linkage with ethylene oxide (EO) was synthesized properties of blend varied with the increasing EO concentration (Guo et al., 2002).

Ring opening copolymerization of $\beta$-butyrolactone produced amorphous PHB-PEG-PHB ATBC. These ATBC nanoparticles (NPs) could be used for hydrophobic drug delivery. Release of pyrene was observed and it showed that release of pyrene from this ATBC showed second order kinetics behavior (Chen et al., 2006).

\subsubsection{Diblock copolymers}

Non-cyclic polyesters with monomethoxy polyethyleneoxide (mPEO) have potential applications in drug release systems Polylactate (PLA) polymers are known as biodegradable and biocompatible polymers. When joined with $\mathrm{mPEO}$ they become potential supplements in drug delivery systems (Zhu et al., 1989). A diblock copolymer PHB-b-mPEO was successfully synthesized and showed capability to self-assemble into nanoparticles and could be used in drug delivery systems and as carriers. Such type of carriers could have a longer lifetime in bloodstreams (Zhu et al., 2004).

A Diblock copolymer PHB-b-mPEG could be fabricated via catalytically transesterification in melt in one step procedure. Depolymerization of PHB can be carried out by two subsequent steps, pyrolysis and transesterification. Such Diblock copolymers were amphiphilic in nature and form colloidal of PHB crystalline (Ravenelle and Marchessault, 2002). 


\subsection{Functionalization of PHAs by thermal degradation}

Thermal degradation of polymers is the deterioration of polymer because of overheating. At high temperature, the degradation of PHAs resulted in monomers, dimers and trimers which are volatile and these monomers readily reacts with one another or other polymers to change the properties of these polymers. This elimination mechanism was analyzed and found mainly dependent on thermal conditions and the oligomers obtained at low temperature, contained an unsaturated group and a carboxylic group linked through an ester linkage, this unsaturated group enhance the degradation of nearby ester linkages. In case of PHB thermal degradation, auto acceleration and auto catalytic effects were observed and followed random scission. PHB degradation at high temperature produced crotonic acid and butyrolactone (BL) (Kopinke et al., 1996; Lehrle and Williams, 1994 Nguyen and Marchessault, 2004; Stromberg et al., 195). At higher temperature, complete degradation of PHB resulted in the production of gases $\left(\mathrm{CO}_{2}\right.$ and $\mathrm{CO})$ along with ketene and ethanol. In one previous concept, it was considered that unsaturated crotonate group of PHAs could not be subjected for free radical polymerization reaction. Nguyen and Marchessault (2004), suggested that PHB with carboxylic acid terminal group can be further subjected for modification, graft polymerization through free radical mechanism in acrylic backbone and PHB side chain copolymers. Poly methyl methacrylate (PMMA) grafted PHB was obtained by free radical grafting method, but it was a copolymer with undetermined molecular weight and high polydispersity; it could be controlled by using atom transfer radical polymerization method (Nguyen and Marchessault, 2005; Nguyen and Marchessault, 2006; Nguyen, 2008).

\subsection{Regeneration of PHAs}

Many cyclic compounds and derivatives of olefins resist polymerization reactions, analysis of this unpolymerization behavior lead to study of polymerization-depolymerization equilibrium studies (Allcock et al., 2003). This behavior of materials lead to the idea of generation of molecular weight controlled polymers under specific conditions. As most of the PHAs are high molecular weight polymers Ryan and McCann (1996) were first to demonstrate that poly(butyl cyanoacrylate) (PBCA) could undergo depolymerization-repolymerization reactions in the presence of a base (THF) and gave monomer of butyl cyanoacrylate (BCA). On addition of tetrabutyle ammonium hydroxide, BCA first polymerize to a high molecular weight monomer 
CdS NPs were proven to be less toxic and could be efficiently used for various biomedical applications such as in treatment of cancer therapies, imaging and other related biological disorders (Pandian et al., 2011). In another study, Zinc oxide reinforced polyhydroxybutyrate-covalerate (PHBV) ZnO-PHBV nanocomposite were successfully fabricated and SEM images confirmed the even distribution ZnO NPs PHBV matrix. The ZnO NPs had increase thermal stability, crystallinity, stiffness and strength and the synthesized nanocomposite could be used in food packaging material (Diez-Pascual and Diez-Vicente). In short, metallization is the most effective way to modify polymers to obtain more functionalized PHAs.

\section{Future perspectives}

Chemical modification of PHAs explored functional PHAs which are suitable for a wide range of applications. Through depolymerization-repolymerization of PHAs molecular weights could be controlled while hydrophobicity could be reduced by carboxylation reactions of unsaturated PHAs. Among PHAs, PHBs are well-known to possess some objectionable properties such as brittleness and crystallinity which can be reduced by blocking or grafting reaction of PHB with other PHAs. Graft/block copolymerization is useful in controlled synthesis of polymer for desired and specific properties. PHAs are auspicious alternator to petroleum-based plastics, but they also have some drawbacks. The major disadvantage of PHAs is their high production cost and low yield of polymer. The purification methods of produced PHAs are also based on high cost purification techniques. Another complication is their proper disposal procedures which needs to be better managed and more cost effective and environmentally sound.

Bacterial PHAs possess a variety of beneficial physical properties making them useful potential materials for various applications. However, lack of functional groups makes them inconvenient for various fields. Alteration methods have been subject for research and discussed during the past few years mainly aiming to reduce the undesired properties, such as crystallinity and mechanical properties which can be altered during their biosynthesis or later by physical or chemical alteration methods. It is expected that more PHAs will be synthesized in the future, It is now possible to yield considerable amount of numerous PHAs, which will allow them to be tried for various applications and levels. The clarification of the PHA synthase mechanism will permit us to get more control over the design and synthesis of novel PHA in future which will aid in their successful use by many industries. 


\section{Concluding remarks}

PHAs alteration is imperative in the different research zones for fabrication of novel polymer composites with diverse properties, such as thermal and mechanical flexibility of the resulting composite materials. Alteration of PHAs through chemical methods is an encouraging methodology to achieve different kinds of composites of PHAs, comprising of an inclusive variety of monomer units for graft/block copolymerization with man-made and further regular polymers that could not be achieved by biological method.

\section{Conflict of interest disclosure}

All the authors disclose no any potential sources of conflict of interest.

\section{Acknowledgement}

The authors acknowledge the Higher Education Commission of Pakistan for the financial support for this study.

\section{References}

Abbate, M., E. Martuscelli, G. Ragosta and G. Scarinzi, 1991. Tensile properties and impact behaviour of poly(3-hydroxybutyrate)/rubber blends. Journal of Materials Science, 26(4): 1119-1125.

Akaraonye, E., T. Keshavarz and I. Roy, 2010. Production of polyhydroxyalkanoates: The future green materials of choice. Journal of Chemical Technology and Biotechnology, 85(6): 732-743.

Aljawish, A., I. Chevalot, B. Piffaut, C. Rondeau-Mouro, M. Girardin, J. Jasniewski, J. Scher and L. Muniglia, 2012. Functionalization of chitosan by laccase-catalyzed oxidation of ferulic acid and ethyl ferulate under heterogeneous reaction conditions. Carbohydrate Polymers, 87(1): 537-544.

Allcock, H.R., F.W. Lampe, J.E. Mark and H. Allcock, Contemporary Polymer Chemistry. Pearson/Prentice Hall Upper Saddle River, New Jersey 2003.

Álvarez-Chávez, C.R., S. Edwards, R. Moure-Eraso and K. Geiser, 2012. Sustainability of biobased plastics: General comparative analysis and recommendations for improvement. Journal of Cleaner Production, 23(1): 47-56. 
Andrade, A.P., B. Witholt, R. Hany, T. Egli and Z. Li, 2002. Preparation and characterization of enantiomerically pure telechelic diols from mcl-poly[(R)-3-hydroxyalkanoates]. Macromolecules, 35(3): 684-689.

Arai, Y., H. Nakashita, Y. Suzuki, Y. Kobayashi, T. Shimizu, M. Yasuda, Y. Doi and I. Yamaguchi, 2002. Synthesis of a novel class of polyhydroxyalkanoates in arabidopsis peroxisomes, and their use in monitoring short-chain-length intermediates of $\beta$-oxidation. Plant and Cell Physiology, 43(5): 555-562.

Arkin, A.H. and B. Hazer, 2002. Chemical modification of chlorinated microbial polyesters. Biomacromolecules, 3(6): 1327-1335.

Arkin, A.H., B. Hazer and M. Borcakli, 2000. Chlorination of poly(3-hydroxy alkanoates) containing unsaturated side chains. Macromolecules, 33(9): 3219-3223.

Arora, D.S. and R.K. Sharma, 2010. Ligninolytic fungal laccases and their biotechnological applications. Applied Biochemistry and Biotechnology, 160(6): 1760-1788.

Ashby, R.D., T.A. Foglia, D.K. Solaiman, C.-K. Liu, A. Nunez and G. Eggink, 2000. Viscoelastic properties of linseed oil-based medium chain length poly(hydroxyalkanoate) films: Effects of epoxidation and curing. International Journal of Biological Macromolecules, 27(5): 355-361.

Azzam, F., L. Heux, J.-L. Putaux and B. Jean, 2010. Preparation by grafting onto, characterization, and properties of thermally responsive polymer-decorated cellulose nanocrystals. Biomacromolecules, 11(12): 3652-3659.

Bhattacharya, A. and B. Misra, 2004. Grafting: A versatile means to modify polymers: Techniques, factors and applications. Progress in Polymer Science, 29(8): 767-814.

Božanić, D., V. Djoković, J. Blanuša, P. Nair, M. Georges and T. Radhakrishnan, 2007. Preparation and properties of nano-sized $\mathrm{Ag}$ and $\mathrm{Ag}_{2} \mathrm{~S}$ particles in biopolymer matrix. The European Physical Journal E: Soft Matter and Biological Physics, 22(1): 51-59. Bugnicourt, E., P. Cinelli, A. Lazzeri and V.A. Alvarez, 2014. Polyhydroxyalkanoate (PHA): Review of synthesis, characteristics, processing and potential applications in packaging. Byrom, D., 1987. Polymer synthesis by microorganisms: Technology and economics. Trends in Biotechnology, 5(9): 246-250.

Cabot, A., R.K. Smith, Y. Yin, H. Zheng, B.M. Reinhard, H. Liu and A.P. Alivisatos, 2008. Sulfidation of cadmium at the nanoscale. ACS Nano, 2(7): 1452-1458. 
Caldwell, G., E.W. Neuse and A.G. Perlwitz, 1997. Water soluble polyamides as potential drug carriers. IX. Polyaspartamides grafted with amine-terminated poly(ethylene oxide) chains. Journal of Applied Polymer Science, 66(5): 911-919.

Chen, C., C.H. Yu, Y.C. Cheng, H. Peter and M.K. Cheung, 2006. Biodegradable nanoparticles of amphiphilic triblock copolymers based on poly(3-hydroxybutyrate) and poly(ethylene glycol) as drug carriers. Biomaterials, 27(27): 4804-4814.

Chiu, H.-J., H.-L. Chen and J. Lin, 2001. Crystallization induced microstructure of crystalline/crystalline poly(vinylidenefluoride)/poly(3-hydroxybutyrate) blends probed by small angle X-ray scattering. Polymer, 42(13): 5749-5754.

Choi, M.H. and S.C. Yoon, 1994. Polyester biosynthesis characteristics of pseudomonas citronellolis grown on various carbon sources, including 3-methyl-branched substrates. Applied and Environmental Microbiology, 60(9): 3245-3254.

Cowie, J.M.G. and Arrighi V, Polymers: Chemistry and Physics of Modern Materials. CRC Press 2007.

Curley, J.M., B. Hazer, R.W. Lenz and R.C. Fuller, 1996. Production of poly(3hydroxyalkanoates) containing aromatic substituents by pseudomonas oleovorans. Macromolecules, 29(5): 1762-1766.

Deng, Y., K. Zhao, X.F., Zhang, P. Hu and G.-Q. Chen, 2002. Study on the three-dimensional proliferation of rabbit articular cartilage-derived chondrocytes on polyhydroxyalkanoate scaffolds. Biomaterials, 23(20): 4049-4056.

Diez-Pascual, A.M. and A.L. Diez-Vicente, 2017. Zinc oxide-reinforced polyhydroxyalkanoates for food packaging applications. International Journal of Food and Biosystems Engineering. 2(1): 2408-0675.

Doi, Y. and C. Abe, 1990. Biosynthesis and characterization of a new bacterial copolyester of 3hydroxyalkanoates and 3-hydroxy-. Omega.-chloroalkanoates. Macromolecules, 23(15): 3705-3707.

Forster, S. and M. Antonietti, 1998. Amphiphilic block copolymers in structure-controlled nanomaterial hybrids. Advanced Materials, 10(3): 195-217.

Gagnon, K., R. Lenz, R. Farris and R. Fuller, 1994. Chemical modification of bacterial elastomers: 1. Peroxide crosslinking. Polymer, 35(20): 4358-4367. 
Gamal, R.F., H.M. Abdelhady, T.A. Khodair, T.S. El-Tayeb, E.A. Hassan and K.A. Aboutaleb, 2013. Semi-scale production of PHAS from waste frying oil by pseudomonas fluorescens S48. Brazilian Journal of Microbiology, 44(2): 539-549.

Goh, S.H., 2014. Miscible polymer blends. In: Polymer blends handbook. Springer: pp: 19152151.

Gonzalez, M., M. Rapado, A.P. Gonzalez and M.G. Perez, 2009. Radiation-induced graft copolymerization of metacrylic acid and butyl methacrylate onto poly(3hydroxybutyrate). International Journal of Polymer Analysis and Characterization, 14(3): 179-195.

Guo, Q., R. Thomann, W. Gronski and T. Thurn-Albrecht, 2002. Phase behavior, crystallization, and hierarchical nanostructures in self-organized thermoset blends of epoxy resin and amphiphilic poly(ethylene oxide)-block-poly(propylene oxide)-block-poly(ethylene oxide) triblock copolymers. Macromolecules, 35(8): 3133-3144.

Hahn, J., A.C. Eschenlauer, M.H. Narrol, D.A. Somers and F. Srienc, 1997. Growth kinetics, nutrient uptake, and expression of the alcaligenes eutrophus poly( $\beta$-hydroxybutyrate) synthesis pathway in transgenic maize cell suspension cultures. Biotechnology Progress, 13(4): 347-354.

Hahn, J., A.C. Eschenlauer, U.B. Sleytr, D.A. Somers and F. Srienc, 1999. Peroxisomes as sites for synthesis of polyhydroxyalkanoates in transgenic plants. Biotechnology Progress, 15(6): 1053-1057.

Han, M.G., S. Kim and S.X. Liu, 2008. Synthesis and degradation behavior of poly(ethyl cyanoacrylate). Polymer Degradation and Stability, 93(7): 1243-1251.

Hay, J. and L. Sharma, 2000. Crystallisation of poly(3-hydroxybutyrate)/polyvinyl acetate blends. Polymer, 41(15): 5749-5757.

Hazer, B. and A. Steinbüchel, 2007. Increased diversification of polyhydroxyalkanoates by modification reactions for industrial and medical applications. Applied Microbiology and Biotechnology, 74(1): 1-12.

Huijberts, G., G. Eggink, P. De Waard, G.W. Huisman and B. Witholt, 1992. Pseudomonas putida kt2442 cultivated on glucose accumulates poly(3-hydroxyalkanoates) consisting of saturated and unsaturated monomers. Applied and Environmental Microbiology, 58(2): 536-544. 
Iqbal, H.M., G. Kyazze, T. Tron and T. Keshavarz, 2014. A preliminary study on the development and characterisation of enzymatically grafted $\mathrm{P}(3 \mathrm{HB})$-ethyl cellulose based novel composites. Cellulose, 21(5): 3613-3621.

Iwata, T., 2015. Biodegradable and bio-based polymers: Future prospects of eco-friendly plastics. Angewandte Chemie International Edition, 54(11): 3210-3215.

Javers, J. and C. Karunanithy, 2012. Polyhydroxyalkanoate production by pseudomonas putida kt217 on a condensed corn solubles based medium fed with glycerol water or sunflower soapstock. Advances in Microbiology, 2(03): 241.

Jendrossek, D. and R. Handrick, 2002. Microbial degradation of polyhydroxyalkanoates. Annual Review of Microbiology, 56(1): 403-432.

Kai, D. and X.J. Loh, 2013. Polyhydroxyalkanoates: Chemical modifications toward biomedical applications. ACS Sustainable Chemistry \& Engineering, 2(2): 106-119.

Kemnitzer, J.E., S.P. McCarthy and R.A. Gross, 1992. Poly (beta-hydroxybutyrate) stereoisomers: A model study of the effects of stereochemical and morphological variables on polymer biological degradability. Macromolecules, ACS Publications, 25 (22): 5927-5934.

Kim, Y.B., R. Lenz and R.C. Fuller, 1992. Poly( $\beta$-hydroxyalkanoate) copolymers containing brominated repeating units produced by pseudomonas oleovorans. Macromolecules, 25(7): 1852-1857.

Klinke, S., Q. Ren, B. Witholt and B. Kessler, 1999. Production of medium-chain-length poly (3hydroxyalkanoates) from gluconate by recombinant escherichia coli. Applied and Environmental Microbiology, 65(2): 540-548.

Kopinke, F.-D., M. Remmler and K. Mackenzie, 1996. Thermal decomposition of biodegradable polyesters - I: Poly( $\beta$-hydroxybutyric acid). Polymer Degradation and stability, 52(1): 25-38.

Kowalczuk, M., G. Adamus and Z. Jedlinski, 1994. Synthesis of new graft polymers via anionic grafting of $\beta$-butyrolactone on poly (methyl methacrylate). Macromolecules, 27(2): 572575.

Kulkarni, S.O., P.P. Kanekar, J.P. Jog, P.A. Patil, S.S. Nilegaonkar, S.S. Sarnaik and P.R. Kshirsagar, 2011. Characterisation of copolymer, poly(hydroxybutyrate-co- 
hydroxyvalerate)(PHB-co-PHV) produced by halomonas campisalis (MCM B-1027), its biodegradability and potential application. Bioresource Technology, 102(11): 6625-6628.

Kumagai, Y. and Y. Doi, 1992. Enzymatic degradation and morphologies of binary blends of microbial poly(3-hydroxy butyrate) with poly( $\varepsilon$-caprolactone), poly(1, 4-butylene adipate and pol (vinyl acetate). Polymer degradation and Stability, 36(3): 241-248.

Kumagai, Y. and Y. Doi, 1993. Synthesis of a block copolymer of poly(3-hydroxybutyrate) and poly(ethylene glycol) and its application to biodegradable polymer blends. Journal of Polymers and the Environment, 1(2): 81-87.

Lageveen, R.G., G.W. Huisman, H. Preusting, P. Ketelaar, G. Eggink and B. Witholt, 1988. Formation of polyesters by pseudomonas oleovorans: Effect of substrates on formation and composition of poly-(R)-3-hydroxyalkanoates and poly-(R)-3-hydroxyalkenoates. Applied and Environmental Microbiology, 54(12): 2924-2932.

Le Fer, G., J. Babinot, D.L. Versace, V. Langlois and E. Renard, 2012. An efficient thiol-ene chemistry for the preparation of amphiphilic pha-based graft copolymers. Macromolecular Rapid Communications, 33(23): 2041-2045.

Leaf, T.A., M.S. Peterson, S.K. Stoup, D. Somers and F. Srienc, 1996. Saccharomyces cerevisiae expressing bacterial polyhydroxybutyrate synthase produces poly-3-hydroxybutyrate. Microbiology, 142(5): 1169-1180.

Lee, J.-Y., Y. Liao, R. Nagahata and S. Horiuchi, 2006. Effect of metal nanoparticles on thermal stabilization of polymer/metal nanocomposites prepared by a one-step dry process. Polymer, 47(23): 7970-7979.

Lee, M.Y. and W.H. Park, 2000. Preparation of bacterial copolyesters with improved hydrophilicity by carboxylation. Macromolecular Chemistry and Physics, 201(18): 27712774.

Lee, S.Y., A. Hassan, I.K. Tan, K. Terakawa, N. Ichikawa and S.N. Gan, 2010. Reactions of palm oil-based mcl-phas with epoxidized natural rubber. Journal of Applied Polymer Science, 115(4): 2039-2043.

Lehrle, R.S. and R.J. Williams, 1994. Thermal-degradation of bacterial poly(hydroxybutyric acid)-mechanisms from the dependence of pyrolysis yields on sample thickness. Macromolecules, 27(14): 3782-3789. 
Levine, A.C., A. Sparano, F.F. Twigg, K. Numata and C.T. Nomura, 2015. Influence of crosslinking on the physical properties and cytotoxicity of polyhydroxyalkanoate (PHA) scaffolds for tissue engineering. ACS Biomaterials Science \& Engineering, 1(7): 567576.

Li, J., X. Li, X. Ni and K.W. Leong, 2003. Synthesis and characterization of new biodegradable amphiphilic poly (ethylene oxide)-b-poly [(r)-3-hydroxy butyrate]-b-poly (ethylene oxide) triblock copolymers. Macromolecules, 36(8): 2661-2667.

Luengo, J.M., B. García, A. Sandoval, G. Naharro and E.R. Olivera, 2003. Bioplastics from microorganisms. Current Opinion in Microbiology, 6(3): 251-260.

Macit, H., B. Hazer, H. Arslan and I. Noda, 2009. The synthesis of PHA-g-(PTHF-b-PMMA) multiblock/graft copolymers by combination of cationic and radical polymerization. Journal of Applied Polymer Science, 111(5): 2308-2317.

Madison, L.L. and G.W. Huisman, 1999. Metabolic engineering of poly (3-hydroxyalkanoates): From DNA to plastic. Microbiology and Molecular Biology Reviews, 63(1): 21-53.

Mittendorf, V., E.J. Robertson, R.M. Leech, N. Krüger, A. Steinbuchel and Y. Poirier, 1998. Synthesis of medium-chain-length polyhydroxyalkanoates in arabidopsis thaliana using intermediates of peroxisomal fatty acid $\beta$-oxidation. Proceedings of the National Academy of Sciences, 95(23): 13397-13402.

Nguyen, S., 2008. Graft copolymers containing poly (3-hydroxyalkanoates)—a review on their synthesis, properties, and applications. Canadian Journal of Chemistry, 86(6): 570-578.

Nguyen, S. and R.H. Marchessault, 2004. Synthesis and properties of graft copolymers based on poly(3-hydroxybutyrate) macromonomers. Macromolecular Bioscience, 4(3): 262-268.

Nguyen, S. and R.H. Marchessault, 2005. Atom transfer radical copolymerization of bacterial poly(3-hydroxybutyrate) macromonomers and methyl methacrylate. Macromolecules, 38(2): 290-296.

Nguyen, S. and R.H. Marchessault, 2006. Graft copolymers of methyl methacrylate and poly ([R]-3-hydroxybutyrate) macromonomers as candidates for inclusion in acrylic bone cement formulations: Compression testing. Journal of Biomedical Materials Research Part B: Applied Biomaterials, 77(1): 5-12.

Nicholson, J.W., 2012. The chemistry of polymers. Royal Society of Chemistry. 
Paglia, E.D., P. Beltrame, M. Canetti, A. Seves, B. Marcandalli and E. Martuscelli, 1993. Crystallization and thermal behaviour of poly (D (-) 3-hydroxybutyrate)/poly (epichlorohydrin) blends. Polymer, 34(5): 996-1001.

Pandian, S.R.K., V. Deepak, K. Kalishwaralal and S. Gurunathan, 2011. Biologically synthesized fluorescent cds nps encapsulated by phb. Enzyme and Microbial Technology, 48(4): 319-325.

Park, W.H., R.W. Lenz and S. Goodwin, 1998. Epoxidation of bacterial polyesters with unsaturated side chains. I. Production and epoxidation of polyesters from 10-undecenoic acid. Macromolecules, 31(5): 1480-1486.

Parvaneh, I., S. Samira and N. Mohsen, 2015. Characterization of ZnS nanoparticles synthesized by co-precipitation method. Chinese Physics B, 24(4): 046104.

Pattabi, M. and J. Uchil, 2000. Synthesis of cadmium sulphide nanoparticles. Solar energy materials and solar cells, 63(4): 309-314.

Peoples, O.P. and A.J. Sinskey, 1989. Poly-beta-hydroxybutyrate (PHB) biosynthesis in alcaligenes eutrophus h16. Identification and characterization of the PHB polymerase gene (PHBC). Journal of Biological Chemistry, 264(26): 15298-15303.

Pfeiffer, D. and D. Jendrossek, 2014. phaM is the physiological activator of poly(3hydroxybutyrate)(PHB) synthase (phaC1) in ralstonia eutropha. Applied and Environmental Microbiology, 80(2): 555-563.

Poirier, Y., 1999. Green chemistry yields a better plastic. Nature Biotechnology, 17(10): 960961.

Poirier, Y., N. Erard and J.M.-C. Petétot, 2001. Synthesis of polyhydroxyalkanoate in the peroxisome of saccharomyces cerevisiae by using intermediates of fatty acid $\beta$-oxidation. Applied and Environmental Microbiology, 67(11): 5254-5260.

Pouton, C.W. and S. Akhtar, 1996. Biosynthetic polyhydroxyalkanoates and their potential in drug delivery. Advanced Drug Delivery Reviews, 18(2): 133-162.

Rai, R., T. Keshavarz, J. Roether, A.R. Boccaccini and I. Roy, 2011. Medium chain length polyhydroxyalkanoates, promising new biomedical materials for the future. Materials

Science and Engineering: R: Reports, 72(3): 29-47. 
Ravenelle, F. and R.H. Marchessault, 2002. One-step synthesis of amphiphilic diblock copolymers from bacterial poly ([R]-3-hydroxybutyric acid). Biomacromolecules, 3(5): 1057-1064.

Riva, S., 2006. Laccases: Blue enzymes for green chemistry. Trends in Biotechnology, 24(5): 219-226.

Robello, D.R., T.D. Eldridge and M.T. Swanson, 1999. Degradation and stabilization of polycyanoacrylates. Journal of Polymer Science Part A: Polymer Chemistry, 37(24): 4570-4581.

Ryan, B. and G. McCann, 1996. Novel sub-ceiling temperature rapid depolymerizationrepolymerization reactions of cyanoacrylate polymers. Macromolecular rapid Communications, 17(4): 217-227.

Sadocco, P., M. Canetti, A. Seves and E. Martuscelli, 1993. Small-angle X-ray scattering study of the phase structure of poly (D (-) 3-hydroxybutyrate) and atactic poly(epichlorohydrin) blends. Polymer, 34(16): 3368-3375.

Sato, S., B. Andreeßen and A. Steinbüchel, 2015. Strain and process development for poly (3HB-co-3HP) fermentation by engineered shimwellia blattae from glycerol. AMB Express, 5(1): 1-9.

Steinbüchel, A., 2005. Non-biodegradable biopolymers from renewable resources: Perspectives and impacts. Current Opinion in Biotechnology, 16(6): 607-613.

Stigers, D.J. and G.N. Tew, 2003. Poly (3-hydroxyalkanoate) (s) functionalized with carboxylic acid groups in the side chain. Biomacromolecules, 4(2): 193-195.

Stromberg, R.R., S. Straus and B.G. Achhammer, 1959. Thermal decomposition of poly (vinyl chloride). Journal of Polymer Science, 35(129): 355-368.

Suriyamongkol, P., R. Weselake, S. Narine, M. Moloney and S. Shah, 2007. Biotechnological approaches for the production of polyhydroxyalkanoates in microorganisms and plants - a review. Biotechnology Advances, 25(2): 148-175.

Tijunelyte, I., J. Babinot, M. Guerrouache, G. Valincius and B. Carbonnier, 2012. Hydrophilic monolith with ethylene glycol-based grafts prepared via surface confined thiol-ene click photoaddition. Polymer, 53(1): 29-36. 
Torres, M.G., J.C. Cortez, M.G. Pérez and R.R. Talavera, 2012. Gamma radiation induced graft copolymerization of typical monomers onto poly(3-hydroxybutyrate). International Journal of Science and Advanced Technology, 2(9): 2221-8386

Torres, M.G., S.V. Muñoz, S.G.S. Rosales, M. del Pilar Carreón-Castro, R.A.E. Muñoz, R.O. González, M.R.E. González and R.R. Talavera, 2015. Radiation-induced graft polymerization of chitosan onto poly(3-hydroxybutyrate). Carbohydrate Polymers, 133: 482-492.

Torres, M.G., J.R.R. Talavera, S.V. Muñoz, M.G. Pérez, M.P.C. Castro, J.C. Cortes and R.A.E. Munoz, 2015. Effects of solvents on the radiation grafting reaction of vinyl compounds on poly(3-hydroxybutyrate). Radiation Physics and Chemistry, 108: 87-94.

Tsuge, T., 2002. Metabolic improvements and use of inexpensive carbon sources in microbial production of polyhydroxyalkanoates. Journal of Bioscience and Bioengineering, 94(6): 579-584.

Wang, Q., Q. Zhuang, Q. Liang and Q. Qi, 2013. Polyhydroxyalkanoic acids from structurallyunrelated carbon sources in escherichia coli. Applied Microbiology and Biotechnology, 97(8): 3301-3307.

Williams, S.F., D.P. Martin, D.M. Horowitz and O.P. Peoples, 1999. PHA applications: Addressing the price performance issue: I. Tissue engineering. International Journal of Biological Macromolecules, 25(1): 111-121.

Wu, C.-S., 2013. Preparation, characterization and biodegradability of crosslinked tea plantfibre-reinforced polyhydroxyalkanoate composites. Polymer degradation and stability, 98(8): 1473-1480.

Yalpani, M., R.H. Marchessault, F.G. Morin and C.J. Monasterios, 1991. Synthesis of poly(3hydroxyalkanoate) (PHA) conjugates: PHA-carbohydrate and PHA-synthetic polymer conjugates. Macromolecules, 24(22): 6046-6049.

Yang, X., K. Zhao and G.-Q. Chen, 2002. Effect of surface treatment on the biocompatibility of microbial polyhydroxyalkanoates. Biomaterials, 23(5): 1391-1397.

Yeo, S., W. Tan, M.A. Bakar and J. Ismail, 2010. Silver sulfide/poly(3-hydroxybutyrate) nanocomposites: Thermal stability and kinetic analysis of thermal degradation. Polymer Degradation and Stability, 95(8): 1299-1304. 
Yu, L., K. Dean and L. Li, 2006. Polymer blends and composites from renewable resources. Progress in Polymer Science, 31(6): 576-602.

Zhu, H., J. Ji and J. Shen, 2004. Biomacromolecules electrostatic self-assembly on 3dimensional tissue engineering scaffold. Biomacromolecules, 5(5): 1933-1939.

Zhu, K., S. Bihai and Y. Shilin, 1989. “Super microcapsules”(SMC). I. Preparation and characterization of star polymethylene oxide (PEO)/polylactide (PLA) copolymers. Journal of Polymer Science Part A: Polymer Chemistry, 27(7): 2151-2159.

Zinn, M. and R. Hany, 2005. Tailored material properties of polyhydroxyalkanoates through biosynthesis and chemical modification. Advanced Engineering Materials, 7(5): 408-411.

Zook, E.C. and B.L. Kee, 2016. Development of innate lymphoid cells. Nature Immunology, 17(7): 775-782. 


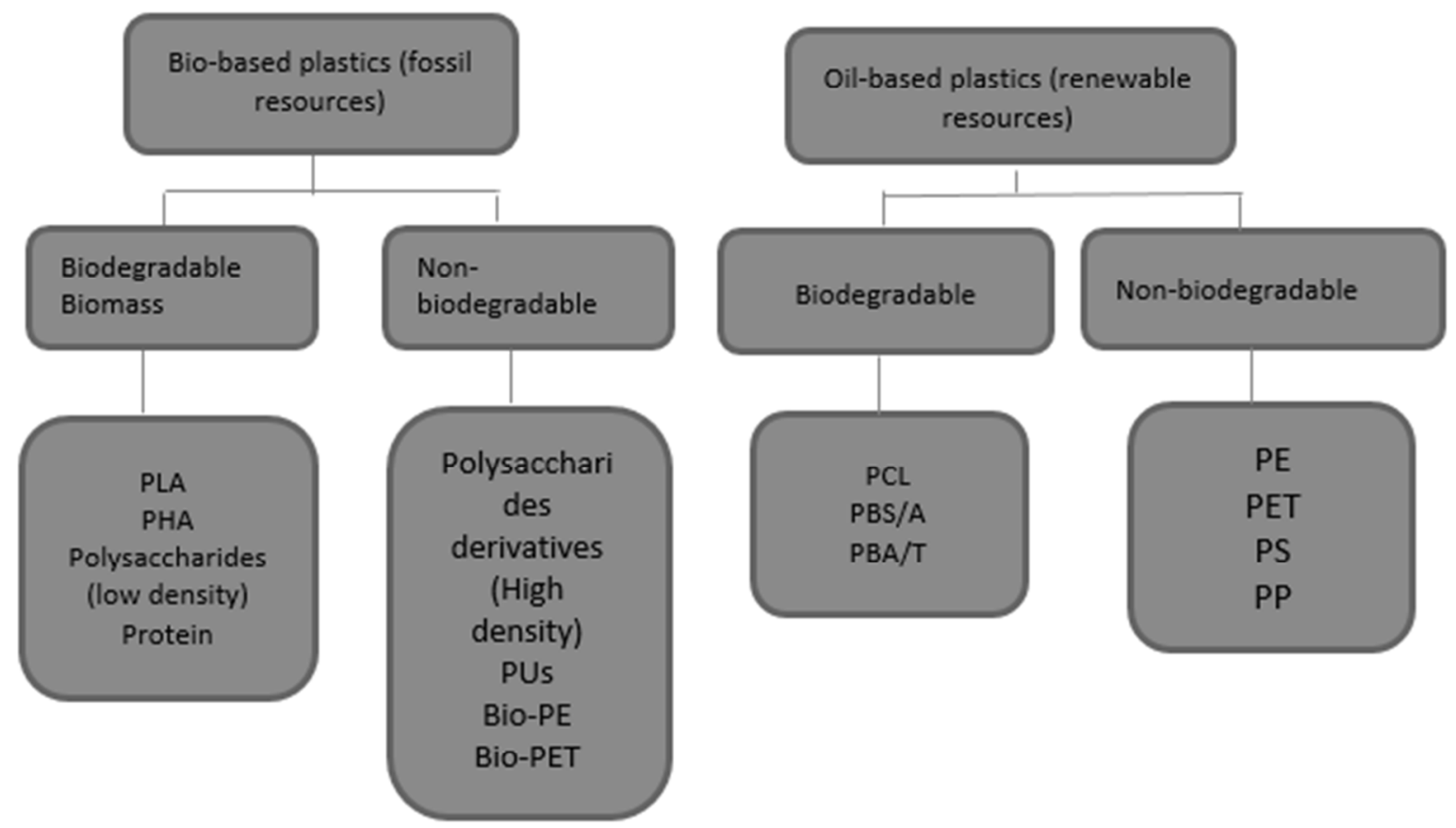

Figure 1. Classification of Plastics (Adapted from Iwata, 2015)

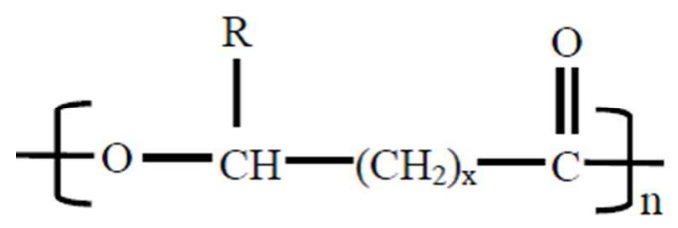

Figure 2. Chemical structure of PHAs. PHAs are generally composed of (R)- $\beta$-hydroxy fatty acids, where the pendant group $(\mathrm{R})$ varies from methyl $(\mathrm{C} 1)$ to tridecyl $(\mathrm{C} 13)$ (Adapted from Madison and Huisman, 1999

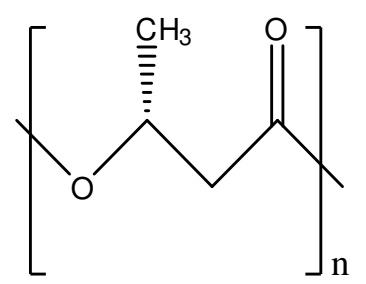

Figure 3. Structure of PHB 
Polymer

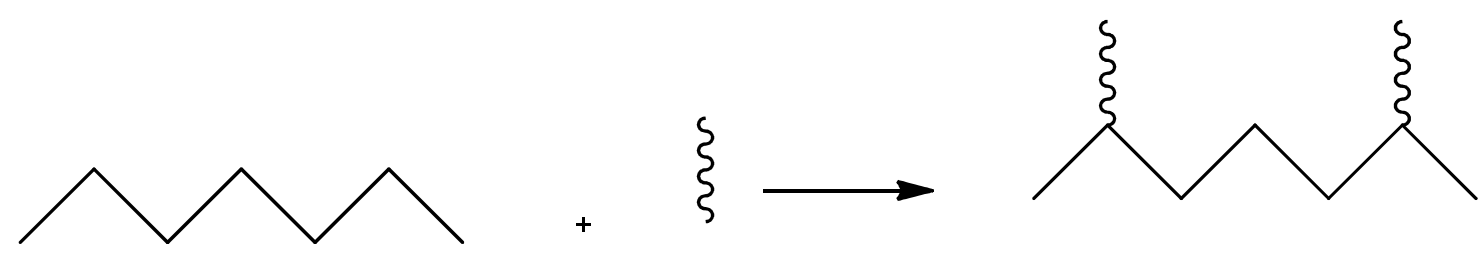

Monomer

Grafted polymer

Figure 4. General mechanism of Grafting (Adapted from Bhattacharya and Misra, 2004)
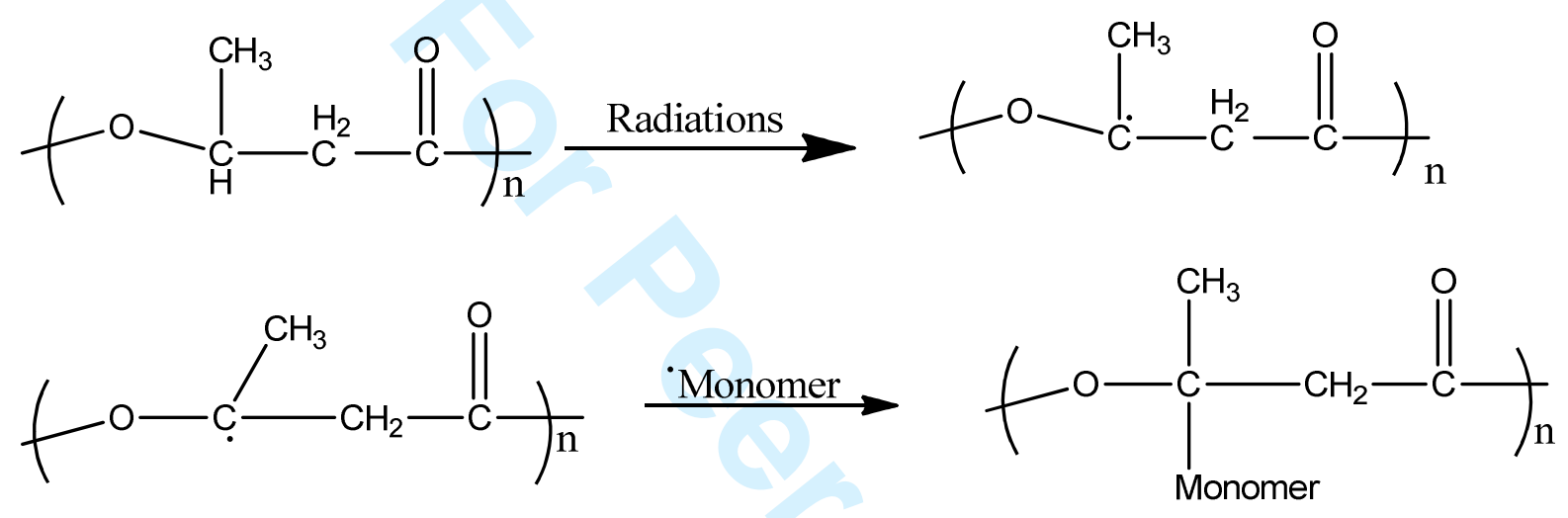

Figure 5. General mechanism of radiation based grafting of PHB (Grafting is also possible at C1 and C3) (Adopted fromTorres et al., 2012)

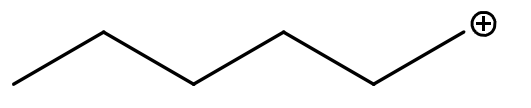

Cationic polymerization

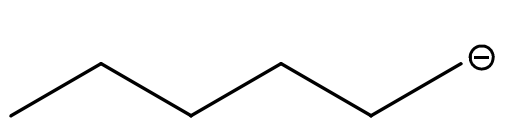

Anionic polymerization

Figure 6. Cationic and anionic polymerization (Allcock et al., 2003) 
Table 1. PHAs Chemical modification methods and properties achieved against each

\begin{tabular}{|c|c|c|c|c|c|c|}
\hline Sr.No & Modification method & $\begin{array}{l}\text { PHA/PHB } \\
\text { based } \\
\text { Substrate }\end{array}$ & $\begin{array}{l}\text { Functional } \\
\text { group }\end{array}$ & Product & Achieved properties & Reference \\
\hline 1 & Epoxidation & $\begin{array}{l}\text { Unsaturate-d } \\
\text { linseed oil } \\
\text { based PHA } \\
\text { (PHA-L) }\end{array}$ & $\begin{array}{l}\text { Epoxide } \\
\text { group }(\mathrm{E})\end{array}$ & PHA-LE & $\begin{array}{l}\text { Increase in tensile strength and } \\
\text { Young's modulus }\end{array}$ & $\begin{array}{l}\text { (Ashby et al., } \\
\text { 2000) }\end{array}$ \\
\hline 2 & Epoxidation/Crosslinking & PHOU & $\begin{array}{l}\text { Anhydride of } \\
\text { succinic acid } \\
\text { (ASA) }\end{array}$ & PHOU-ASA & $\begin{array}{l}\text { Increase in sol-gel contents and } \\
\text { glass transition temperature }\end{array}$ & $\begin{array}{l}\text { (Arkin et al., } \\
\text { 2000). }\end{array}$ \\
\hline 3 & Epoxidation/crosslinking & PHO-co-UD & peroxides & $\begin{array}{l}\text { PHO-co- } \\
\text { UD/Peroxides }\end{array}$ & $\begin{array}{l}\text { Decrease in tensile strength and } \\
\text { tear resistance }\end{array}$ & $\begin{array}{l}\text { (Gagnon et al., } \\
\text { 1994) }\end{array}$ \\
\hline 4 & Crosslinking & PHA-g-MA & TPF & $\begin{array}{l}\text { PHA-g-MA/t- } \\
\text { TPF }\end{array}$ & $\begin{array}{l}\text { Increase in water resistance and } \\
\text { biodegradability, lower viscosity }\end{array}$ & (Wu, 2013) \\
\hline 5 & Crosslinking & $\mathrm{PHB} / \mathrm{PHBU}$ & Thiolene & PHB/PHBU & $\begin{array}{l}\text { Decreased toxicity and increased } \\
\text { biocompatibility }\end{array}$ & $\begin{array}{l}\text { (Levine et al., } \\
\text { 2015) }\end{array}$ \\
\hline 6 & Carboxylation & PHO-co-PHU & $\begin{array}{l}\mathrm{OsO}_{4} \text { and } \\
\text { oxone }\end{array}$ & $\begin{array}{l}\text { Carboxylated } \\
\text { PHOU }\end{array}$ & Decrease in hydrophobicity & $\begin{array}{l}\text { (Stigers and Tew, } \\
\text { 2003) }\end{array}$ \\
\hline 7 & Carboxylation & PHOU & $\mathrm{KMnO}_{4}$ & $\begin{array}{l}\text { Carboxylated } \\
\text { PHOU }\end{array}$ & $\begin{array}{l}\text { Decrease in hydrophobicity, low } \\
\text { molecular weight polymer }\end{array}$ & $\begin{array}{l}\text { (Lee and Park, } \\
\text { 2000) }\end{array}$ \\
\hline 8 & Chlorination & PHA & Chlorine gas & PHA-Cl & $\begin{array}{l}\text { Increase in crystallinity, brittleness } \\
\text { and hardness }\end{array}$ & $\begin{array}{l}\text { (Arkin et al., } \\
2000)\end{array}$ \\
\hline
\end{tabular}




\begin{tabular}{|c|c|c|c|c|c|c|}
\hline 9 & Chlorination & $\mathrm{PHO}$ & Chlorine gas & $\mathrm{PHO}-\mathrm{Cl}$ & $\begin{array}{l}\text { Increase in glass transition and } \\
\text { melting temperature }\end{array}$ & $\begin{array}{l}\text { (Arkin and Hazer, } \\
\text { 2002) }\end{array}$ \\
\hline 10 & Chlorination & PHB & Chlorine gas & PHB-Cl & $\begin{array}{l}\text { Decrease in melting temperature } \\
\text { and increase in glass transition } \\
\text { temperature }\end{array}$ & $\begin{array}{l}\text { (Arkin and Hazer, } \\
\text { 2002) }\end{array}$ \\
\hline 11 & Radiation based grafting & PHB & $\begin{array}{l}\text { MA and } \\
\text { BuMA }\end{array}$ & $\begin{array}{l}\text { PHB-g-MA } \\
\text { and PHB-g- } \\
\text { BuMA }\end{array}$ & $\begin{array}{l}\text { Increase in hydrophilicity and } \\
\text { decrease in crystallinity }\end{array}$ & $\begin{array}{l}\text { (Gonzalez et al., } \\
\text { 2009) }\end{array}$ \\
\hline \multirow[t]{2}{*}{12} & Radiation based grafting & PHB & PVA & PHB-g-PVA & Increase in biodegradability & $\begin{array}{l}\text { (Torres et al., } \\
\text { 2015) }\end{array}$ \\
\hline & Radiation based grafting & PHB & Chitosan (CS) & PHB-g-CS & Increase in crystallinity & Torres et al., 2015 \\
\hline 13 & $\begin{array}{l}\text { Free radical based } \\
\text { grafting }\end{array}$ & PHB & PMMA & $\begin{array}{l}\text { PHB-g- } \\
\text { PMMA }\end{array}$ & $\begin{array}{l}\text { Decrease in glass tranition } \\
\text { temperature }\end{array}$ & $\begin{array}{l}\text { (Nguyen and } \\
\text { Marchessault, } \\
\text { 2004) }\end{array}$ \\
\hline 14 & Anionic grafting & PMMA & $\begin{array}{l}\beta- \\
\text { Butyrolacton } \\
(\mathrm{BL})\end{array}$ & PMMA-g-BL & Saponification & $\begin{array}{l}\text { (Kowalczuk et al., } \\
\text { 1994). }\end{array}$ \\
\hline 15 & Cationic grafting & PHA & $\begin{array}{l}\text { THF and } \\
\text { PMMA }\end{array}$ & $\begin{array}{l}\text { (PHA-g- } \\
\text { (PTHF-b- } \\
\text { PMMA) }\end{array}$ & $\begin{array}{l}\text { Multi-graft copolymer and } \\
\text { controlled molecular weight } \\
\text { copolymer }\end{array}$ & $\begin{array}{l}\text { (Macit et al., } \\
\text { 2009) }\end{array}$ \\
\hline 16 & Enzymatic grafting & PHB & $\begin{array}{l}\text { Ethylcellulose } \\
\text { (EC) laccase } \\
\text { enzyme }\end{array}$ & PHB-g-EC & $\begin{array}{l}\text { Increase in mechanical properties } \\
\text { and decrease in crystallinity }\end{array}$ & (Iqbal et al., 2014) \\
\hline 17 & Thiolation & PHOU & Jaffamine & $\begin{array}{l}\text { PHOU-g- } \\
\text { thiolated }\end{array}$ & $\begin{array}{l}\text { Amphiphilic and thermosensitive } \\
\text { copolymer }\end{array}$ & $\begin{array}{l}\text { Le Fer et al., } \\
\text { 2012) }\end{array}$ \\
\hline
\end{tabular}




\begin{tabular}{|c|c|c|c|c|c|c|}
\hline & & & & jaffamine & & \\
\hline 18 & Thiolation & PNAS & $\begin{array}{l}\text { EDMA and } \\
\text { thiolated EG }\end{array}$ & $\begin{array}{l}\text { poly(NAS-co- } \\
\text { EDMA) }\end{array}$ & Increase in hydrophilicity & $\begin{array}{l}\text { (Tijunelyte } \text { et al., } \\
\text { 2012) }\end{array}$ \\
\hline 19 & Blending & PHB & PHBHHx & $\begin{array}{l}\mathrm{PHB} / \mathrm{PHBHHx} \\
\text { films }\end{array}$ & $\begin{array}{l}\text { Increased biocompatibility and } \\
\text { tensile strength }\end{array}$ & $\begin{array}{l}\text { (Deng et al., } \\
\text { 2002) }\end{array}$ \\
\hline 20 & Blending & PHB & EPR & $\begin{array}{l}\mathrm{PHB} / \mathrm{EPR} \\
\text { blend }\end{array}$ & Decrease in melting point & (Goh, 2014) \\
\hline 21 & Esterification & PHB-OH & $\mathrm{mPEO}$ & ATBC & Increased thermal stability & (Li et al., 2003) \\
\hline 22 & Esterification & PHB & $\mathrm{mPEO}$ & PHB-b-mPEO & Increased life time & (Zhu et al., 2004) \\
\hline 23 & Esterification & PHB & mPEG & PHB-b-mPEG & Amphiphilic block co polymer & $\begin{array}{l}\text { (Ravenelle and } \\
\text { Marchessault, } \\
\text { 2002) }\end{array}$ \\
\hline 24 & Thermal degradation & PHB & - & $\begin{array}{l}\text { Crotonic acid } \\
\text { and } \\
\text { butyrolactone }\end{array}$ & $\begin{array}{l}\text { Molecular weight controlled } \\
\text { polymer/monomer }\end{array}$ & $\begin{array}{l}\text { (Kopinke et al., } \\
\text { 1996) }\end{array}$ \\
\hline 25 & Regeneration & PBCA & THF (as base) & $\mathrm{BCA}$ & $\begin{array}{l}\text { Molecular weight controlled } \\
\text { polymer/monomer }\end{array}$ & $\begin{array}{l}\text { Ryan and } \\
\text { McCann, 1996) }\end{array}$ \\
\hline 26 & Regeneration & PECA & $\mathrm{THF}$ & ECA & $\begin{array}{l}\text { Molecular weight controlled } \\
\text { polymer/monomer }\end{array}$ & (Han et al., 2008) \\
\hline 27 & Metallization & PS & $\mathrm{Pd}$ & PS-Pd & Thermal degradation decreased & (Lee et al., 2006) \\
\hline 28 & Metallization & PP & $\mathrm{Pd}$ & PP-Pd & Thermal degradation decreased & (Lee et al., 2006 \\
\hline
\end{tabular}




\section{Page 41 of 41}

Biotechnology Progress

\begin{tabular}{lllllll}
\hline 29 & Metallization & MMA & Pd & MMA-Pd & Thermal degradation decreased \\
\hline 30 & Metallization & PET & Pd & PET-Pd & Thermal degradation increased \\
\hline 31 & Metallization & PA & Pd & PA-Pd & Thermal degradation increased \\
\hline
\end{tabular}

41

John Wiley \& Sons 